\title{
Chromatin restriction by the nucleosome remodeler Mi-2 $\beta$ and functional interplay with lineage-specific transcription regulators control B-cell differentiation
}

\author{
Toshimi Yoshida, ${ }^{1}$ Yeguang Hu, ${ }^{1,6}$ Zhihong Zhang, ${ }^{1,6}$ Akinola O. Emmanuel, ${ }^{2,6}$ Kiriaki Galani, ${ }^{1}$ \\ Brejnev Muhire, ${ }^{3}$ Hugo J. Snippert, ${ }^{1,4}$ Christine J. Williams, ${ }^{1}$ Michael Y. Tolstorukov, ${ }^{3,5}$ Fotini Gounari, ${ }^{2}$ \\ and Katia Georgopoulos \\ ${ }^{1}$ Cutaneous Biology Research Center, Massachusetts General Hospital, Harvard Medical School, Charlestown, Massachusetts \\ 02129, USA; ${ }^{2}$ Knapp Center for Lupus Research, Department of Medicine, Section of Rheumatology, The University of Chicago, \\ Chicago, Illinois 60637, USA; ${ }^{3}$ Department of Molecular Biology, Massachusetts General Hospital, Harvard Medical School, \\ Boston, Massachusetts 02144, USA
}

Coordinated induction, but also repression, of genes are key to normal differentiation. Although the role of lineagespecific transcription regulators has been studied extensively, their functional integration with chromatin remodelers, one of the key enzymatic machineries that control chromatin accessibility, remains ill-defined. Here we investigate the role of $\mathrm{Mi}-2 \beta$, a SNF-2-like nucleosome remodeler and key component of the nucleosome remodeling and histone deacetylase (NuRD) complex in early B cells. Inactivation of Mi-2 $\beta$ arrested differentiation at the large pre-B-cell stage and caused derepression of cell adhesion and cell migration signaling factors by increasing chromatin access at poised enhancers and chromosome architectural elements. Mi-2 $\beta$ also supported IL-7R signaling, survival, and proliferation by repressing negative effectors of this pathway. Importantly, overexpression of Bcl2, a mitochondrial prosurvival gene and target of IL-7R signaling, partly rescued the differentiation block caused by Mi-2 $\beta$ loss. Mi-2 $\beta$ stably associated with chromatin sites that harbor binding motifs for IKAROS and EBF1 and physically associated with these transcription factors both on and off chromatin. Notably, Mi-2 $\beta$ shared loss-of-function cellular and molecular phenotypes with IKAROS and EBF1, albeit in a distinct fashion. Thus, the nucleosome remodeler Mi-2 $\beta$ promotes pre-B-cell differentiation by providing repression capabilities to distinct lineage-specific transcription factor-based regulatory networks.

[Keywords: Mi-2 $\beta$ (CHD4); NuRD; IKAROS; EBF1; chromatin restriction; cell cycle; apoptosis; metabolism; IL-7R signaling]

Supplemental material is available for this article.

Received November 9, 2018; revised version accepted April 15, 2019.

Commitment and differentiation into the B-cell lineage take place within the bone marrow (BM) of adult mammals and are regulated by an orderly induction of B-cell lineagespecific transcription factors, recombination factors, and signaling molecules. In turn, these support the sequential rearrangement of immunoglobulin heavy chain (Igh) and immunoglobulin light chain (Igl) genes, formation of preB-cell receptor (pre-BCR) and BCR signaling complexes that further advance B-cell differentiation, and suppres-

Present addresses: ${ }^{4}$ Department of Molecular Cancer Research, University Medical Center Utrecht, 3584 CX Utrecht, The Netherlands; ${ }^{5}$ Department of Informatics, Dana-Farber Cancer Institute, Boston, Massachusetts 02215 , USA.

${ }^{6}$ These authors contributed equally to the work.

Corresponding authors: katia.georgopoulos@cbrc2.mgh.harvard.edu, toshimi.yoshida@cbrc2.mgh.harvard.edu

Article published online ahead of print. Article and publication date are online at http://www.genesdev.org/cgi/doi/10.1101/gad.321901.118. sion of transcriptional programs that promote alternative cell fates such as myeloid. These transcriptional regulatory events, both positive and negative, promote B-cell precursor survival, expansion, and differentiation and selection of an immature B-cell repertoire that undergoes further maturation at peripheral lymphoid organs. IKAROS, E2A, EBF1, FOXO1, PAX5, AIOLOS, LEF1, and IRF4 are among the transcription regulators that induce and reinforce the molecular signatures required for early B-cell differentiation (Kee 2009; Medvedovic et al. 2011; Mercer et al. 2011; Welinder et al. 2011; Georgopoulos 2017). Loss of function in these transcriptional regulators

(C) 2019 Yoshida et al. This article is distributed exclusively by Cold Spring Harbor Laboratory Press for the first six months after the full-issue publication date (see http://genesdev.cshlp.org/site/misc/terms.xhtml). After six months, it is available under a Creative Commons License (Attribution-NonCommercial 4.0 International), as described at http://creativecommons.org/licenses/by-nc/4.0/. 
arrests differentiation at discrete steps both prior to and after B-cell lineage commitment, indicating a nonredundant participation of these factors in this developmental process. Human leukemias that derive from early steps in B-cell differentiation frequently harbor inactivating mutations in these transcription regulators, highlighting their importance in promoting progression through differentiation intermediates that are potentially leukemogenic (Mullighan 2012).

IKAROS (Ikzf1) and AIOLOS (Ikzf3), members of the IKAROS gene family, are among the early acting transcriptional regulators that induce lymphoid fate and differentiation (Georgopoulos et al. 1994; Wang et al. 1996, 1998; Georgopoulos 2017). The role of IKAROS in hematopoietic stem cells (HSCs) and multipotent progenitors is to prime expression of lymphoid lineage-promoting genes and attenuate expression of genes implicated in self-renewal and myeloid differentiation (Yoshida et al. 2006; Ng et al. 2009). Loss of IKAROS in the HSC compartment converts lymphoid-primed multipotent progenitors (LMPPs) into myeloid precursors. At subsequent stages of B-cell differentiation, IKAROS and AIOLOS are required for transition from the highly proliferative large pre-B-cell to the quiescent small pre-B-cell stage (Joshi et al. 2014; Schwickert et al. 2014). Loss of IKAROS in early B-cell precursors causes a block in pre-B-cell differentiation, with a dramatic gain in cell adhesion and self-renewal supported by aberrant induction of genes involved in adhesion signaling, extracellular matrix organization, and actin cytoskeleton regulation and down-regulation of pre-B-cell signaling and differentiation factors (Joshi et al. 2014; Schwickert et al. 2014).

In T cells, IKAROS proteins stably associate with the nucleosome remodeling and histone deacetylase (NuRD) complex through direct binding to the ATP-dependent nucleosome remodeler Mi-2 $\beta$ (CHD4) (Kim et al. 1999; Koipally and Georgopoulos 2002; Sridharan and Smale 2007; Zhang et al. 2012). The PHD and chromodomains of Mi$2 \beta$ can support binding of the NuRD complex to nucleosomes and methylated histones (Mansfield et al. 2011; Watson et al. 2012). The presence of IKAROS in the NuRD complex can provide additional targeting to IKAROS DNA-binding sites and increase the chromatin residence of the remodeler in a lineage-specific fashion. Loss of Mi-2 $\beta$ interferes with the transition from doublenegative (DN) to double-positive (DP) thymocytes, alters the production of $\mathrm{CD}^{+}{ }^{+} \mathrm{T}$ cells and interferes with the ability of mature T cells to proliferate (Williams et al. 2004). In contrast, loss of IKAROS has almost the opposite effect, as it accelerates differentiation through the DN to DP stage and facilitates T-cell activation and proliferation in response to TCR signaling (Avitahl et al. 1999; Winandy et al. 1999; Harker et al. 2002; Naito et al. 2007). In T-cell precursors, Mi- $2 \beta$ is enriched at IKAROS-binding sites in the vicinity of transcriptionally active lymphoid genes that, upon IKAROS depletion, show loss in expression and increase in NuRD remodeling and modifying activities (Zhang et al. 2012). These observations suggest that in the context of actively expressed genes, the colocalization of Mi-2 $\beta$ and IKAROS may serve as a harbinger for gene repression at a subsequent step in differentiation, as shown with embryonic stem cells and neurons (Whyte et al. 2012; Yamada et al. 2014).

Here we examine the role of Mi- $2 \beta$ in early B-cell differentiation and show that it is required for differentiation from the pro-B to the small pre-B-cell stage. Mi- $2 \beta$ plays a major role in chromatin restriction and repression of genes supporting cell adhesion and migration but is also involved in the positive regulation of cell growth and survival. This key role of Mi- $2 \beta$ in early B-cell differentiation can be attributed to its interactions with IKAROS and EBF1 at poised enhancers that restrict expression of gene networks regulated by these lineage-specific DNA-binding factors.

\section{Results}

\section{$\mathrm{Mi}-2 \beta$ is required for differentiation into the small pre- $B$-cell stage}

The role of Mi-2 $\beta$ in early B-cell differentiation was addressed by analyzing mice with conditional inactivation of the ATPase domain, starting either at the HSC $\left(C h d 4^{\mathrm{fl} / \mathrm{fl}} ; M x-C r e\right.$; referred to here as $\left.\Delta C h d 4^{M x}\right)$, in early lymphoid progenitors $\left(\mathrm{Chd} 4^{\mathrm{fl} / \mathrm{fl}}\right.$; Cd2-Cre; referred to here as $\left.\Delta \mathrm{Chd} 4^{\mathrm{Cd} 2}\right)$, or in committed pro-B-cell precursors $\left(\mathrm{Chd} 4^{\mathrm{fl} / \mathrm{fl}}\right.$; Cd19-Cre; referred to here as $\Delta$ Chd4 ${ }^{\text {Cd19 }}$ ) (Fig. 1A; Rickert et al. 1997; de Boer et al. 2003; Williams et al. 2004; Yoshida et al. 2008). An increase in common lymphoid progenitors (CLPs; Lin ${ }^{-/ \mathrm{lo}} \mathrm{IL}-7 \mathrm{Ra}^{+} \mathrm{Sca}-1^{\mathrm{lo}} \mathrm{c}-\mathrm{Kit}^{\mathrm{lo}}$ ) was detected in both $\Delta C h d 4^{M x}$ and $\Delta C h d 4^{C d 2}$ relative to wild-type (WT) mice (Supplemental Fig. S1A; data not shown). The identity of these early lymphoid progenitors in the $\Delta C h d 4^{M x}$ mouse model was validated by testing for increased expression of B-cell differentiation markers (i.e., $I 17 r$, Dntt, and Ebf1) and reduced expression of myeloid differentiation genes (i.e., Mpo) (Supplemental Fig. S1B).

The majority of B cells in the BM of $\Delta C h d 4^{C d 2}$ mice expressed CD19, CD43, c-Kit, and IL-7Ra, cell surface markers of the pro-B-cell stage (Fig. 1A-C; Hardy et al. 1991; Rolink et al. 1994). In contrast, the majority of WT BM B cells were $\mathrm{CD} 19^{+}, \mathrm{CD}_{4}{ }^{-}$, and $\mathrm{c}-\mathrm{Kit}^{-}$and expressed CD2 and CD25, markers of the small pre-B-cell stage (Fig. 1AC). We further evaluated the effect of $\mathrm{Mi}-2 \beta$ deletion at the pro-B-to-small pre-B-cell transition (Fig. 1A). Due to deregulation of BP1 expression (a marker of large pre-B cells) in $\Delta C h d 4^{C d 2}$ B-cell precursors, we used an alternative strategy to evaluate differentiation. Pre-B cells $\left(\mathrm{CD}_{19}{ }^{+} \mathrm{c}-\mathrm{Kit}^{-/ \mathrm{lo}} \mathrm{IgM}^{-}\right)$were subdivided into two populations based on CD2 expression (Fig. 1C; Supplemental Fig. S1C). Small pre-B cells $\left(\mathrm{CD} 19^{+} \mathrm{c}-\mathrm{Kit}^{-} \mathrm{CD} 2^{+} \mathrm{IgM}^{-}\right)$ were the largest of the two populations in WT, whereas large pre-B cells $\left(\mathrm{CD} 19^{+} \mathrm{c}-\mathrm{Kit}^{-/{ }^{\circ}} \mathrm{CD} 2^{-} \mathrm{IgM}^{-}\right)$were the major population in $\Delta C h d 4^{C d 2} \mathrm{BM}$ (Fig. 1C). The large preB-cell-containing population was further subdivided into large pre-B cells $\left(\mathrm{CD} 19^{+} \mathrm{c}-\mathrm{Kit}^{-/{ }^{l o}} \mathrm{CD} 2^{-} \mathrm{CD} 43^{+}\right)$and transitional to small pre-B cells $\left(\mathrm{CD} 19^{+} \mathrm{c}-\mathrm{Kit}^{-} \mathrm{CD} 2^{-} \mathrm{CD} 43^{-}\right)$, the combination of which we refer to as "large transitional" $\left(\mathrm{CD} 19^{+} \mathrm{c}-\mathrm{Kit}^{-/ \mathrm{lo}} \mathrm{CD} 43^{+}\right.$and $\left.{ }^{-} \mathrm{CD} 2^{-}\right)$pre-B cells. 
A

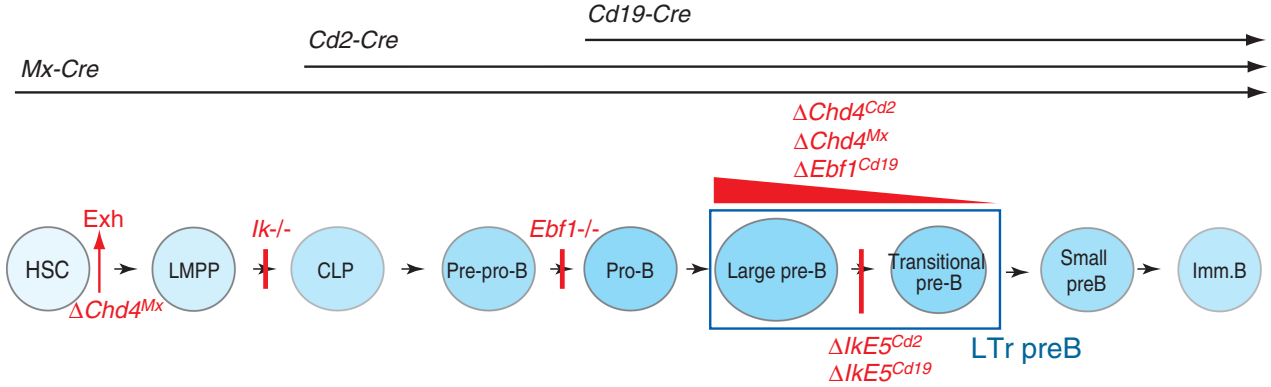

\begin{tabular}{|c|c|c|c|c|}
\hline $\begin{array}{l}\text { Lin }^{-} \\
\text {C-Kit }^{\text {hi }} \\
\text { Sca-1 } \\
\text { Flt3- }\end{array}$ & $\begin{array}{l}\text { Lin }^{-} \\
\text {C-Kit }^{\text {hi }} \\
\text { Sca-1 } \\
\text { Flt3 }^{+}\end{array}$ & $\begin{array}{l}\mathrm{Lin}^{-1 / 0} \\
\text { c-Kit' } \\
\text { Sca-1 } \\
\text { IL-7R }\end{array}$ & $\begin{array}{l}\text { B220+ } \\
\text { CD19- } \\
\text { C-Kito }^{-} \\
\text {IL-7R }^{+}\end{array}$ & $\begin{array}{l}\text { B220+ } \\
\text { CD19+ } \\
\text { c-Kit }^{+} \\
\text {CD43 }^{+} \\
\text {BP1- }^{-} \\
\text {CD2 } \\
\text { CD25- }\end{array}$ \\
\hline & $\begin{array}{l}\lg h \\
\lg \end{array}$ & $\begin{array}{c}G L(D-J) \\
G L\end{array}$ & $\begin{array}{l}D-J \\
G L\end{array}$ & $\begin{array}{r}V D J \\
G L\end{array}$ \\
\hline
\end{tabular}

B

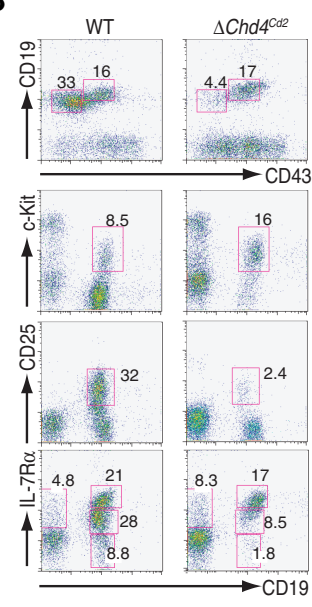

C

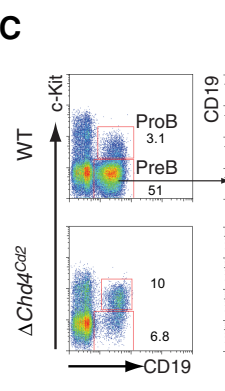

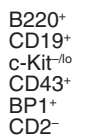

\section{CD19+
$\mathrm{C}^{+} \mathrm{Kit}^{-10}$}

$\mathrm{CD}^{4} 3^{+}$
$\mathrm{BP}^{+}$

$\mathrm{BP} 1^{+}$
$\mathrm{CD}{ }^{-}$

VDJ

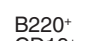

\section{$\mathrm{B} 220^{+}$
$\mathrm{CD} 19^{+}$}

CD19+
C-Kit

C-Kit
CD43-

$\mathrm{CD} 43^{-}$
$\mathrm{BP} 1^{+}$

$\mathrm{BP} 1^{+}$
$\mathrm{CD} 2^{-}$

CD2
CD25-

VDJ

\section{$\mathrm{B} 220^{+}$}

$\begin{array}{ll}\text { B220 } & \text { B220 } \\ \text { CD19+ } & \text { B }\end{array}$

C-Kit $\quad$ CD19-

$\mathrm{BP} 1+$

$\mathrm{CD}^{+}$
$\mathrm{CD}^{+} 5^{+}$

$\mathrm{CD}^{\circ} 5^{+}$
$\operatorname{lgM}^{-}$

VDJ

$\mathrm{CD}^{+}$
$\mathrm{lgM}{ }^{+}$

$\frac{\operatorname{lgM}^{+}}{\lg ^{-}}$

VDJ

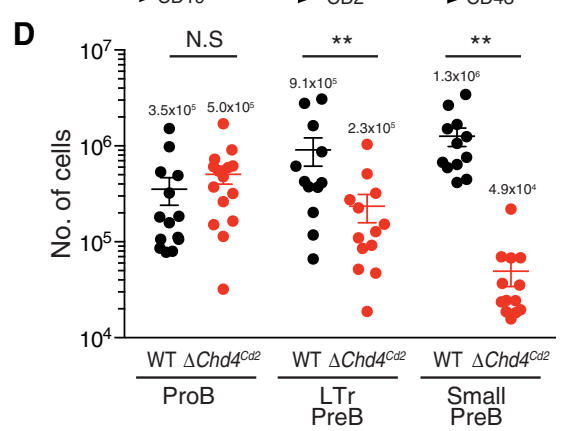

Figure 1. Mi-2 $\beta$ is required for differentiation into a small pre-B cell. $(A)$ Schematic representation of early B-cell differentiation as defined

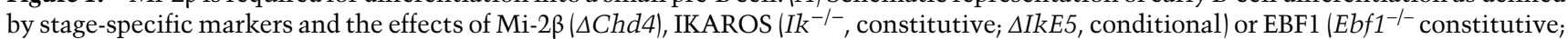
$\triangle E b f 1$, conditional) inactivation. Arrows above the diagram indicate the stages in differentiation at which $M x-C r e, C d 2-C r e$, and Cd19Cre are active. Precursors in transition from pro-B to small pre-B are marked by a blue box outline. Differentiation block is depicted by either a red bar (acute) or a long red arrowhead (gradual), and the type of Cre responsible for the effect is shown as a superscript. A population increase caused by mutation is shown by a red upward-pointing arrow. (Imm.B) Immature B cells; (Exh) exhaustion. (B, $C$ ) Flow cytometric analysis of BM cells from WT and $\Delta C h d 4^{C d 2}$ mice with stage-specific markers (as described in $A$ ) that identify pro-B (i.e.,

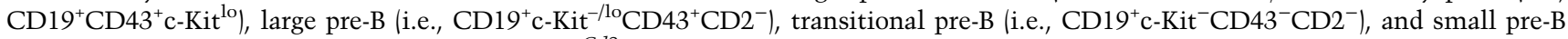
(i.e., $\mathrm{CD} 19^{+} \mathrm{CD} 43^{-} \mathrm{CD} 2^{+} \mathrm{CD} 25^{+} \mathrm{IgM}^{-}$) cells. $\Delta \mathrm{Chd} 4^{\mathrm{Cd} 2} \mathrm{CD} 19^{+} \mathrm{c}-\mathrm{Kit}^{-} \mathrm{CD} 2^{-} \mathrm{B}$-cell precursors show an intermediate expression of $\mathrm{CD} 43$, indicating a differentiation block between large and small pre-B. $(D)$ Absolute cell numbers for pro-B, "large transitional" (LTr) pre-B, and small pre-B cells in two femurs and tibias from WT and $\Delta C h d 4^{C d 2}$ mice. The average and standard deviation (SD) are indicated for each population. Unpaired $t$-test (two-tailed) was used for statistical analysis. Twelve to 14 animals were analyzed for both WT and $\Delta C h d 4{ }^{C d 2}$ mice. (N.S.) Nonsignificant; $\left(^{*}\right) P<0.05 ;\left(^{* * *}\right) P<0.002$.

Although the absolute number of pro-B cells $\left(\mathrm{CD} 19^{+} \mathrm{C}-\mathrm{Kit}^{\mathrm{lo}} \mathrm{CD} 43^{+}\right)$was not significantly changed in the $\Delta C h d 4^{C d 2} \mathrm{BM}$, the number of large transitional pre-B cells and small pre-B cells was progressively reduced (from fourfold to 26-fold) (Fig. 1D). A similar arrest between the pro-B and small pre-B-cell stage was observed in the $\Delta C h d 4^{M x}$ mouse model, which deletes from the
HSC compartment (Supplemental Fig. S1D, $\Delta C h d 4^{M x}$; Yoshida et al. 2008).

In sharp contrast to the $\Delta C h d 4^{C d 2}$ and $\Delta C h d 4^{M x}$ mouse models, deletion of Mi- $2 \beta$ with Cd19-Cre starting at pro-B cells resulted in no significant arrest in small pre-B-cell differentiation (Supplemental Fig. S1D, $\Delta C h d 4^{\text {Cd19 }}$ ). Thus, the requirement for $\mathrm{Mi}-2 \beta$ in pre-B-cell differentiation is 
rooted in the CLP or early pro-B cell, and subsequent Mi- $2 \beta$ depletion does not interfere with normal differentiation.

\section{$M i-2 \beta$ is not required for expression of the pre-BCR complex}

Productive recombination at the $I g h$ locus (Fig. 2A) is a prerequisite for pre-B-cell differentiation. Sequential rearrangements of $D-I_{H}$ and $V-D I_{H}$ in early pro-B cells are responsible for the production of IgH chains that associate with surrogate light chains to form the pre-BCR. Expression of pre-BCR signals the proliferative expansion and differentiation of large to small pre-B cells (Fig. 1A; Schatz 2004; Herzog et al. 2009). Loss of function of the recombination-activating gene Rag1 causes loss of pre-BCR signaling and a block in differentiation prior to the large pre-B-cell stage (Spanopoulou et al. 1994).

Pro-B cells were sorted from WT and $\Delta C h d 4^{C d 2}$ mice,

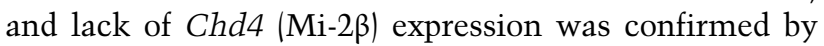
semiquantitative RT-PCR (Fig. 2B). An increase in expression of the Chd4 homolog Chd3 (Mi-2a) was seen. Germline $I g h$ transcripts were used as indicators of chromatin accessibility and transcriptional activity. I $\mu$ transcripts transcribed from the $E \mu$ intronic enhancer were similar in expression between WT and $\Delta C h d 4^{C d 2}$ pro-B cells, whereas the $\mu 0$ germline transcripts showed an increase in the mutant pro-B cells (Fig. 2B).

$V D J$ rearrangements were tested using genomic DNA isolated from the same samples (Fig. 2C). $D_{h}-I_{h}$ and $V$-DI rearrangements involving the two most proximal $V_{h}$ members $\left(V_{h}\right.$ Q52 and $\left.V_{h} 7183\right)$ were observed at similar frequencies in WT and $\Delta C h d 4^{C d 2}$ pro-B cells (Fig. 2C). $V$ - $D J$ rearrangements to the distal $V_{h} 558$ family were reduced by twofold to threefold in $\Delta C h d 4^{C d 2}$ compared with WT pro-B cells. Nonetheless, intracellular IgM expression was comparable in WT and $\Delta C h d 4^{C d 2}$ pro-B cells and small pre-B cells, although the latter population was greatly reduced in $\Delta C h d 4^{C d 2}$ mice (Fig. 2D).

Expression of surrogate light chains was tested as a potential defect in pre-BCR complex signaling. Expression of $\lambda 5$ (Igll1) and VpreB (Vpreb1) was either comparable or increased in $\Delta C h d 4^{C d 2}$ pro-B cells and large transitional preB cells compared with WT (Fig. 2E; Supplemental Fig. $\mathrm{S} 2 \mathrm{~A}$. Expression of other key regulators of early B-cell differentiation, such as Flt3,Il7r, Ebf1, and Pax5 and the recombination enzymes Rag1, Rag2, and Dntt, were also either unaffected or increased in the $\Delta C h d 4^{C d 2}$ B-cell precursors (Fig. 2E; Supplemental Fig. S2A). $\Delta C h d 4^{C d 2}$ mice were crossed to the D23 transgenic line $\left(\Delta C h d 4^{C d 2}\right.$; D23 $\mathrm{tg}$ ) that expresses a prerearranged Igк chain to see whether it could rescue the differentiation block. In spite of Igк expression, $\Delta C h d 4^{C d 2}$; D23 tg pro-B cells $\left(\mathrm{CD} 19^{+} \mathrm{c}-\mathrm{Kit}^{\mathrm{int}}\right)$ maintained a block in differentiation (Supplemental Fig. $\mathrm{S} 2 \mathrm{~B}, \mathrm{CD} 19^{+} \mathrm{c}-\mathrm{Kit}^{-} \mathrm{CD}{ }^{+}$).

Although Mi-2 $\beta$ is critical for pre-B-cell differentiation, it is not required for Igh recombination or expression of the pre-BCR signaling complex. Thus, Mi- $2 \beta$ may control pathways that operate either downstream from or independently of pre-BCR signaling and which are required for pre-B-cell differentiation.

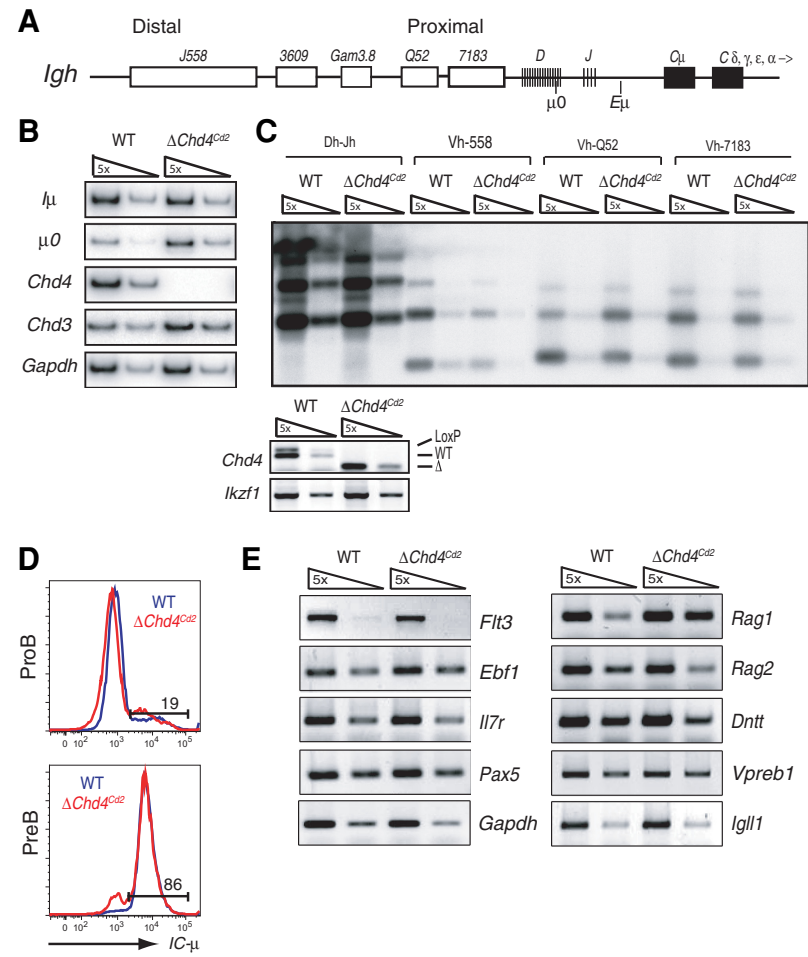

Figure 2. Igh rearrangement is not dependent on Mi-2 $\beta$. (A) Diagram of $I g h$ locus depicting proximal and distal $V, D$, and $J$ clusters tested for recombination. The five $V_{H}$ families are represented by white boxes, and the $D, J$, and $C$ regions are shown by black boxes. Rearrangement of the most distal variable gene $\left(V_{H^{-}} 558\right)$ and the two most proximal $\left(V_{H^{-}} \mathrm{Q} 52\right.$ and $V_{H^{-}}$7183) was analyzed. The initiation sites for the $\mu O$ and $I \mu$ germline transcripts are depicted. $(B)$ Semiquantitative RT-PCR analyses for Igh germline transcripts, Chd4, and its homolog, Chd3, in pro-B cells from WT and $\Delta C h d 4^{C d 2}$ mice. Fivefold dilutions of cDNA were used, and samples were normalized using Gapdh expression. (C) VDI rearrangement in WT and $\Delta C h d 4^{C d 2}$ pro-B cells. (Top) Normalized genomic DNA samples from sorted pro-B populations were analyzed for rearrangement by PCR amplification followed by Southern blotting. Fivefold dilutions of gDNA were used for PCR amplification. Rearrangement of $D-J$ as well as $V_{H-}$ $558, V_{H^{-}} \mathrm{Q} 52$, and $V_{H^{-}} 7183$ to $D /$, respectively, is shown for both WT and $\Delta C h d 4^{C d 2}$. (Bottom) The deletion of the ATPase subunit of Mi-2 $\beta$ (CHD4) was verified by PCR amplification of exons 1123. The samples were normalized to an amplified $I k z f 1$ fragment. (D) Flow cytometry for expression of intracellular IgM $(I C \mu)$ in pro-B and small pre-B cells from WT and $\Delta C h d 4^{C d 2}$ mice. Numbers indicate the percentage of cells in the $I C \mu$-high gate. (E) Semiquantitative RT-PCR analyses for early B-cell differentiation markers (Flt3, I17r, Ebf1, and Pax5), key regulators for Ig recombination, and pre-BCR complex components (Rag1, Rag2, Dntt, Vpreb1, and Igll1) in pro-B cells from WT and $\Delta C h d 4^{C d 2}$ mice. Fivefold dilutions of cDNA were used, and the samples were normalized using Gapdh expression.

\section{Large pre-B-cell proliferation and survival require Mi- $2 \beta$}

Proliferation and survival of early B-cell precursors are dependent on both pre-BCR and IL-7R signaling. This combination of signaling pathways is critical for generating a 
large pool of small pre-B cells in which Igl rearrangement and B-cell selection can take place.

A $30 \%$ reduction in the proliferation of $\Delta C h d 4^{C d 2}$ pro-B cells $\left(\mathrm{CD} 19^{+} \mathrm{c}-\mathrm{Kit}^{\mathrm{int}} \mathrm{CD} 43^{+}\right)$was seen relative to $\mathrm{WT}$ (Fig. 3A; Supplemental Fig. S3A). Proliferation was further decreased (by 2.6-fold) in $\Delta C h d 4^{\mathrm{Cd} 2}$ large transitional pre-B cells (Fig. 3A). Although no significant increase in proapoptotic $\left(\right.$ Annexin $V^{+}$) cells was seen ex vivo (Fig. 3B; Supplemental Fig. S3A), $\Delta C h d 4^{C d 2}$ pro-B and large transitional pre-B cells did not survive in culture even when grown in the presence of IL-7 and BM stroma. After $24 \mathrm{~h}$ in culture, the numbers of proapoptotic and dead cells were significantly increased in $\Delta C h d 4^{C d 2}$ pro-B-cell cultures compared with WT (Fig. 3C).
Large pre-B-cell survival and proliferation are normally dependent on IL-7R and pre-BCR signaling that induce a transcriptional response by activating STAT5, the PI3KAKT, and MAPK signaling pathways (Corfe and Paige 2012). Both IL-7R and pre-BCR components were expressed in $\Delta C h d 4^{C d 2}$ large transitional pre-B cells (Figs. 1B, 2; Supplemental Fig. S2A). Signaling downstream from these receptors was tested by sorting and stimulating large transitional pre-B cells from WT and $\Delta C h d 4^{C d 2} \mathrm{BM}$ with IL-7 and anti-Ig $\beta$ followed by protein analysis by Western blotting and fluorescent-activating cell sorting (FACS). A reduction in both pSTAT5 and pAKT was seen by both methods in $\Delta C h d 4^{C d 2}$ large transitional pre-B cells relative to WT, indicative of a defect in IL-7R signaling (Fig.
A

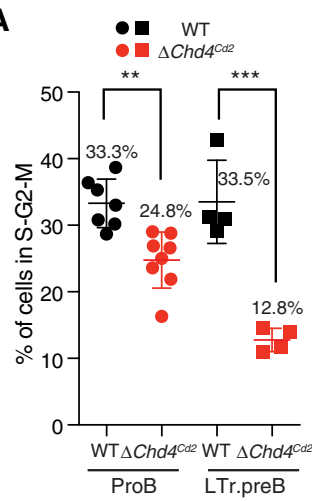

B

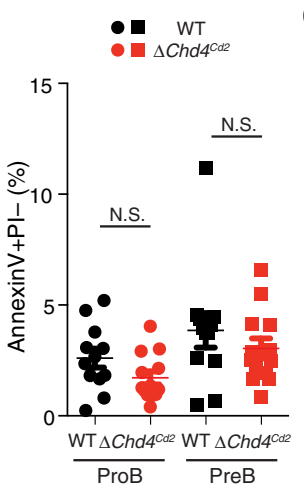

C

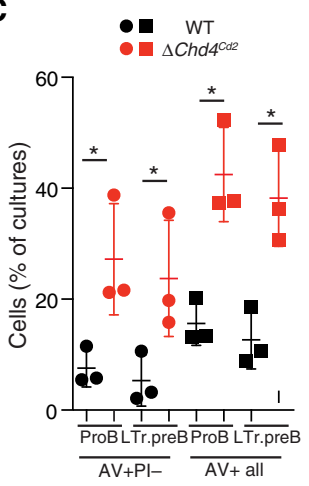

D
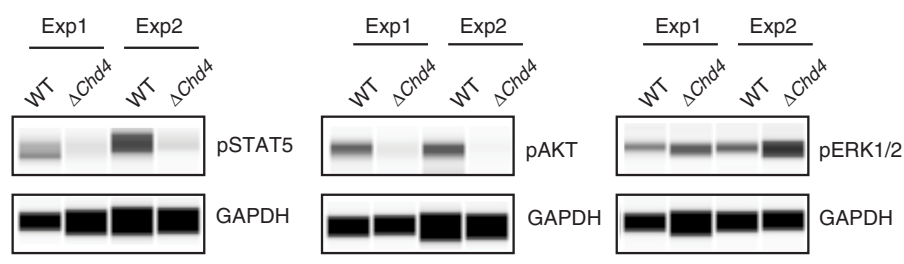

E

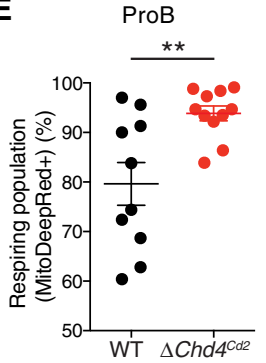

$\mathbf{F}$
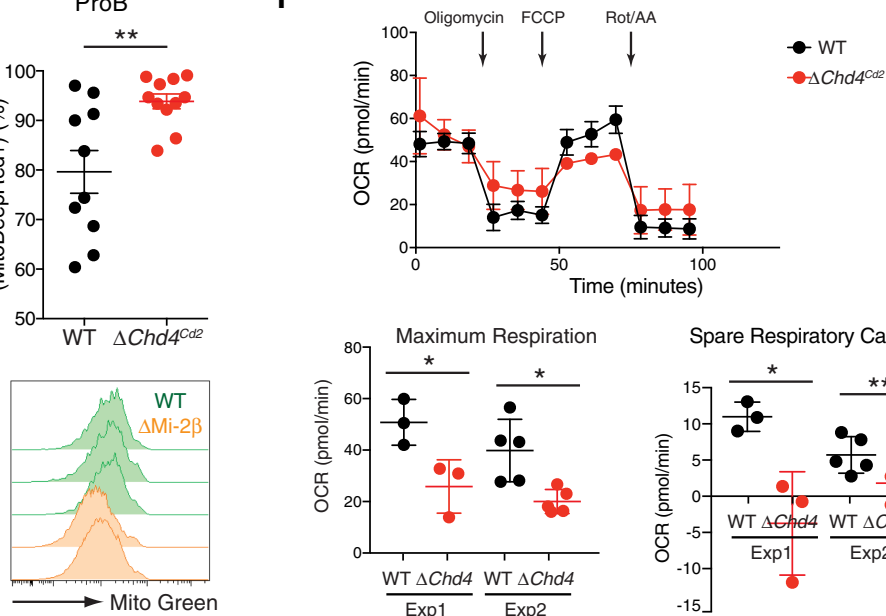
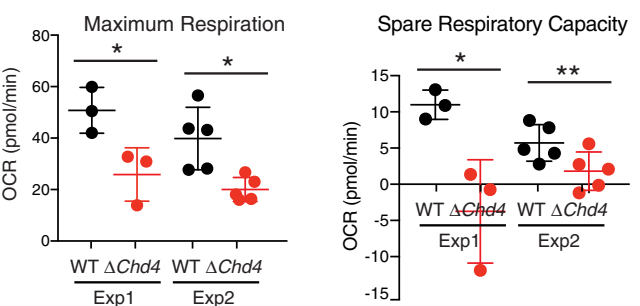

Figure 3. Proliferation and survival of pre-B-cell precursors are dependent on $\mathrm{Mi}-2 \beta$. (A) Cell cycle analyses for ex vivo WT and $\Delta C h d 4^{C d 2}$ pro-B and large transitional (LTr) pre-B cells sorted from WT and $\Delta C h d 4^{C d 2}$ (as defined in Fig. 1C) using propidium iodide (PI). Statistical analyses of the percentage of $\mathrm{S}_{-}$ $\mathrm{G}_{2} \mathrm{M}$ cycling cells for each cell type are shown. Each data point corresponds to one experimental animal. $\left(^{* *}\right) P<0.002 ;\left({ }^{* * *}\right) P<0.001$. Unpaired $t$-test (two-tailed) was used for statistical analysis. Seven and eight animals were analyzed for pro-B cells from WT and $\Delta C h d 4^{C d 2}$ mice, respectively. Four mice each were analyzed for large transitional (LTr) B cells from WT and $\Delta C h d 4^{C d 2}$ mice. $(B)$ The percentages of Annexin $\mathrm{V}^{+} \mathrm{PI}^{-}$apoptotic fractions of ex vivo pro-B and pre-B from WT and $\Delta C h d 4^{C d 2}$ mice are shown. (N.S.) Nonsignificant. Unpaired $t$-test (twotailed) was used for statistical analysis. Ten and 11 mice were analyzed for B-cell precursors from WT and $\Delta C h d 4^{C d 2}$ mice, respectively. $(C)$ The percentages of apoptotic (AnnexinV $\mathrm{PI}^{-}\left[\mathrm{AV}^{+} \mathrm{PI}^{-}\right]$) or apoptotic and dead $\left(\mathrm{AnnexinV}^{+}\left[\mathrm{AV}^{+}\right.\right.$all]) cells within pro-B and large transitional (LTr) pre-B cells cultured in the presence of IL-7 on OP9-GFP stroma are shown. The majority of cells became Annexin $\mathrm{V}^{+}\left(\mathrm{AV}^{+}\right)$within $24 \mathrm{~h}$ of culture. (D) Analysis of the IL-7R and pre-BCR signaling in pre-B-cell precursors sorted from WT and $\Delta C h d 4^{C d 2}$ mice $(\Delta C h d 4)$ by automated Western blotting. Cells were stimulated by IL-7 and anti-Ig $\beta$ (CD79b) for $5 \mathrm{~min}$ at $37^{\circ} \mathrm{C}$ prior to lysis. The levels of phospho-STAT5 and phospho-AKT signaling events triggered by IL-7R engagement and of phosho-ERK1/2 (MAPK) by pre-BCR were tested. Two representative experiments are shown. (M) Molecular weight markers. (E, top) Analysis of pro-B cells from WT and $\Delta C h d 4^{C d 2}$ mice active in mitochondrial respiration identified by positive staining with MitoTracker Deep Red by flow cytometry. The percentage of actively respiring cells is provided with mean and standard deviation for $11 \mathrm{WT}$ and $\Delta C h d 4^{\mathrm{Cd} 2}$ mice analyzed. Unpaired $t$-test (two-tailed) was used for statistical analysis. $(* *) P<0.001$. (Bottom) The total mitochondrial mass of pro-B cells from WT and $\Delta C h d 4^{C d 2}$ mice was estimated by staining with MitoTracker Green. Histograms from a representative experiment are shown. $(F)$ The oxygen consumption rate (OCR) for $1.5 \times 10^{5}$ pre-B-cell precursors sorted from WT and $\Delta C h d 4^{C d 2}$ mice $(\Delta C h d 4)$ was measured by the Mito stress test in the Seahorse $\mathrm{XF}^{\mathrm{e}} 24$ analyzer. OCR kinetics prior to and after addition of oligomycin, carbonyl cyanide p-trifluoromethoxyphenylhydrazone (FCCP), and rotenone and antimycin A (Rot/AA) are shown at the top. The deduced maximum and spare respiratory capacities are shown at the bottom. $\left(^{* *}\right) P<0.002 ;\left({ }^{*}\right) P<0.05$. 
3D; Supplemental Fig. S3B). In contrast, MAPK signaling, measured by pERK phosphorylation, was increased in $\Delta C h d 4^{C d 2}$ relative to WT pre-B cells, indicating a potential increase in pre-BCR signaling (Fig. 3D).

The effect of dysfunctional IL-7R signaling on mitochondrial biogenesis was evaluated as a potential cause for the decrease in survival of $\Delta C h d 4^{C d 2} \mathrm{~B}$-cell precursors. $\Delta C h d 4^{C d 2}$ pro-B cells displayed a lower total mitochondrial mass by MitoTracker Green but showed a relative increase in actively respiring mitochondria by MitoTracker Deep Red staining (Fig. 3E; Supplemental Fig. S3C,D). Mitochondrial metabolism was further evaluated by measuring oxygen consumption of sorted $\Delta C h d 4^{C d 2}$ and WT B-cell precursors stimulated with IL-7 and treated sequentially with pharmacological agents that inhibit or stimulate the mitochondrial membrane electron transport chain and ATP production. Although basal respiration was not significantly different between $\Delta C h d 4^{C d 2}$ and WT pre-B cells, both maximum respiratory capacity and spare respiratory capacity, measures of cellular fitness, were significantly reduced (Fig. 3F). Additionally, the extracellular acidification rate (ECAR), an indicator of anaerobic glycolysis, was significantly reduced in the $\Delta C h d 4^{C d 2}$ compared with WT pre-B cells (Supplemental Fig. S3E).

Taken together, these studies indicate that during the pro-B-to-pre-B-cell transition, the IL-7R-AKT signaling axis is dependent on Mi-2 $\beta$. Dysfunctional IL-7R signaling in $\Delta C h d 4^{C d 2}$ large transitional pre-B cells is likely responsible for defects in cellular metabolism and fitness that contribute to diminished survival of the mutant B-cell precursors.

\section{Transcriptional effects of Mi-2 $\beta$ loss in pre-B-cell} precursors

Mi-2 $\beta$ is an ATP-dependent nucleosome remodeler that modulates chromatin accessibility and, thereby, transcriptional output. Comparative analysis of the transcriptional profiles of pro-B and large transitional pre-B cells revealed that they were highly correlated with each other in both WT and $\Delta C h d 4^{C d 2}$ mutant mice, supporting their correct assignment in the B-cell differentiation hierarchy (Fig. 4A).

Nonetheless, a number of normally repressed genes were significantly up-regulated in $\Delta C h d 4^{C d 2}$ pro-B (1024) and large transitional pre-B (1439) cells compared with WT (Fig. 4B; Supplemental Tables S1, S2). A smaller number of genes were down-regulated in $\triangle C h d 4^{C d 2}$ pro-B (404) and large transitional pre-B (322) compared with WT (Fig. 4B; Supplemental Tables S1, S2). Down-regulated genes exhibited a smaller change in expression compared with up-regulated genes in $\Delta C h d 4^{C d 2}$ B-cell precursors (Fig. 4B; Supplemental Fig. S4A).

The majority of up-regulated genes were actively repressed by Mi- $2 \beta$ in both $\Delta C h d 4^{C d 2}$ pro-B and large transitional pre-B cells (807 out of 1024 or 1439) (Fig. 4C). A small subset of these genes was developmentally repressed during the pro-B-to-large pre-B-cell transition but failed to become so in the absence of Mi-2 $\beta$ (346 out of 1439) (Fig. 4C). Both of these categories of up-regulated genes (actively and developmentally repressed) were involved in cell adhesion and cell migration (Fig. 4C; Supplemental Fig. S4B). Pathways involved in the positive regulation of cell death and negative regulation of cell growth were also up-regulated in $\Delta C h d 4^{C d 2}$ pro-B and large transitional pre-B cells (Supplemental Fig. 4B), consistent with the observed defects in proliferation and survival seen in the absence of Mi-2 $\beta$ and IL-7R signaling. An increase in expression of the negative regulators of IL-7R signaling (Socs2 and Socs3) that function by inhibiting induction of JAK-STAT was detected (Fig. 8A, below; Supplemental Fig. 4B).

Genes that were down-regulated in $\Delta C h d 4^{C d 2}$ pro-B or large transitional pre-B cells and therefore are dependent on Mi- $2 \beta$ for expression were divided into three subsets. One subset was normally induced in large transitional pre-B cells and consisted of regulators of pre-BCR signaling and lymphocyte differentiation (Fig. 4D, pre-B differentiation, 107; Supplemental Fig. S4B). A second subset was specifically down-regulated in $\Delta C h d 4^{C d 2}$ large transitional pre-B cells (94) and consisted of genes involved in cell cycle and DNA metabolism (Fig. 4D, $\Delta$ Chd4 LTr, 94; Supplemental Fig. S4B). Loss in expression of these genes correlated with the severe loss in proliferation seen in $\Delta C h d 4^{C d 2}$ large transitional pre-B cells (Figs. 3A [2.6-fold down], 4D [down, 94]; Supplemental Fig. S4B). The third subset of down-regulated genes was common to both $\Delta C h d 4^{C d 2}$ pro-B and large transitional pre-B cells and was involved in glutathione metabolism that regulates oxidative stress (Fig. 4D, common $\Delta C h d 4$ pro-B and LTr pre-B cells, 121; Supplemental Fig. S4B,C; Shah et al. 2013).

Thus, Mi- $2 \beta$ actively represses an extensive repertoire of genes involved in cell adhesion, migration, cell death and negative regulation of cell growth in pre-B-cell precursors. Mi- $2 \beta$ is also required for expression of a small cohort of genes that support proliferation, control oxidative stress, and promote pre-B-cell differentiation.

\section{Association of Mi-2 $\beta$ with lineage-specific and chromosome-organizing factors}

To evaluate the mechanisms by which $\mathrm{Mi}-2 \beta$ regulates transcription during B-cell differentiation, we examined its chromatin distribution in WT large pre-B cells. Genomic annotation of Mi- $2 \beta$ chromatin enrichment peaks indicated its presence at both promoter-distal and promoterproximal sites (Fig. 5A). K-means clustering of histone modifications and transcription factors at significantly enriched Mi- $2 \beta$ sites categorized them into four types of regulatory elements (Fig. 5B): poised enhancers (C3: $\mathrm{H} 3 \mathrm{~K} 4 \mathrm{me}^{++}, \mathrm{H} 3 \mathrm{~K} 4 \mathrm{me} 2^{+}, \mathrm{H} 3 \mathrm{~K} 4 \mathrm{me} 3^{-}, \mathrm{H} 3 \mathrm{~K} 27 \mathrm{ac}^{+}$, and $\left.\mathrm{RNApII}^{+-}\right)$, inactive enhancers (Cl: H3K4mel ${ }^{+}$, $\mathrm{H} 3 \mathrm{~K} 4 \mathrm{me}^{+/-}$, H3K4me3 ${ }^{-}, \mathrm{H} 3 \mathrm{~K} 27 \mathrm{ac}^{-}$, and $\mathrm{RNApII}^{-}$), active promoters $\left(\mathrm{C} 2\right.$ and $\mathrm{C} 5: \mathrm{H} 3 \mathrm{~K} 4 \mathrm{me}^{-}, \mathrm{H} 3 \mathrm{~K} 4 \mathrm{me}^{++}$, $\mathrm{H} 3 \mathrm{~K} 4 \mathrm{me} 3^{++}, \mathrm{H} 3 \mathrm{~K} 27 \mathrm{ac}^{++}$, and $\mathrm{RNApII}^{++}$, and CTCF-only sites $\left(\mathrm{C} 4: \mathrm{CTCF}^{++}, \mathrm{H} 3 \mathrm{~K} 4 \mathrm{me}^{-}{ }^{-}, \mathrm{H} 3 \mathrm{~K} 4 \mathrm{me}^{-}{ }^{-}, \mathrm{H} 3 \mathrm{~K}_{2} 7 \mathrm{ac}^{-}\right.$, and $\left.\mathrm{RNApII}^{-}\right)$. Coenrichment of $\mathrm{Mi}-2 \beta$ with B-cell lineage transcription regulators and especially IKAROS was particularly prominent at poised enhancers (C3) (Fig. 5B). 
A

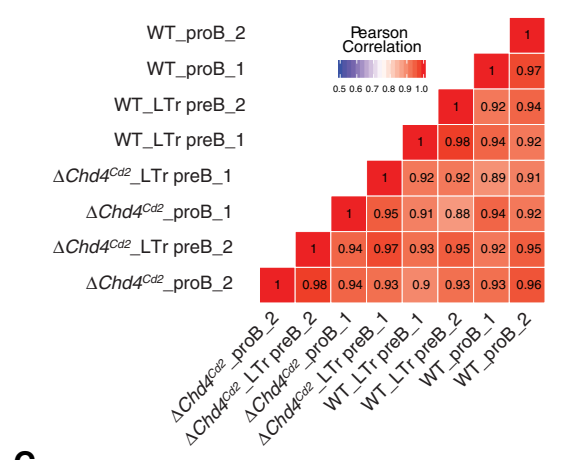

B

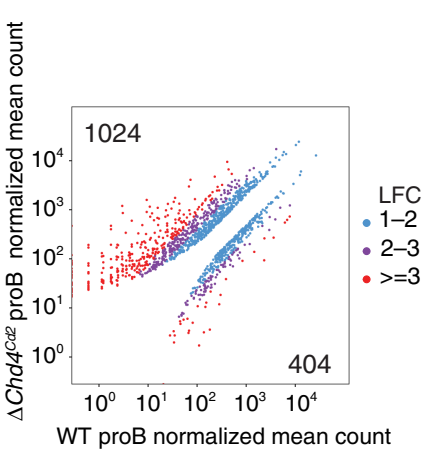

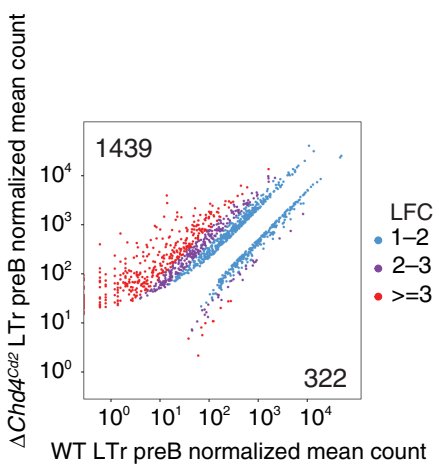

C

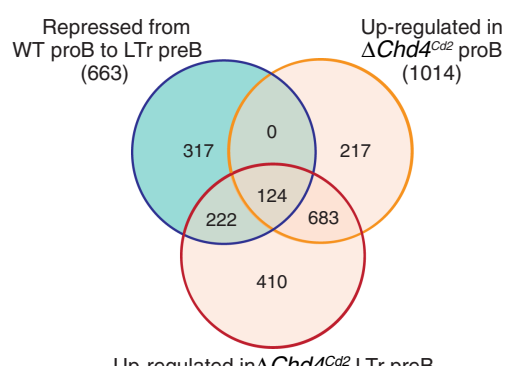

Up-regulated in $\triangle C h d 4^{C d 2} \mathrm{LTr}$ preB (1439)

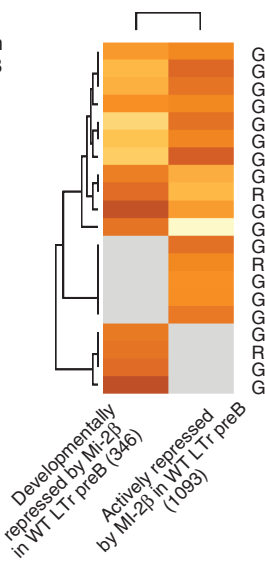

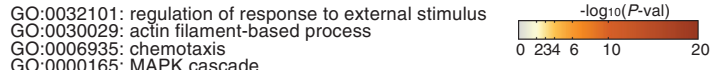

GO:000165: MAPK cascade GO:0007169: transmembrane receptor protein tyrosine kinase signaling pathway GO:0098609: cell-cell adhesion GO: 0043410: positive regulation of MAPK cascade GO:0030334: regulation of cell migration GO:0050769: positive regulation of neurogenesis GO:0051924: regulation of calcium ion transport R-MMU-112316: Neuronal System G.1990778: protein localization to cell periphery GO:009611: response to wounding membrane adhesion molecules R-MMU-416482: G alpha (12/13) signalling events GO:0060485: mesenchyme development
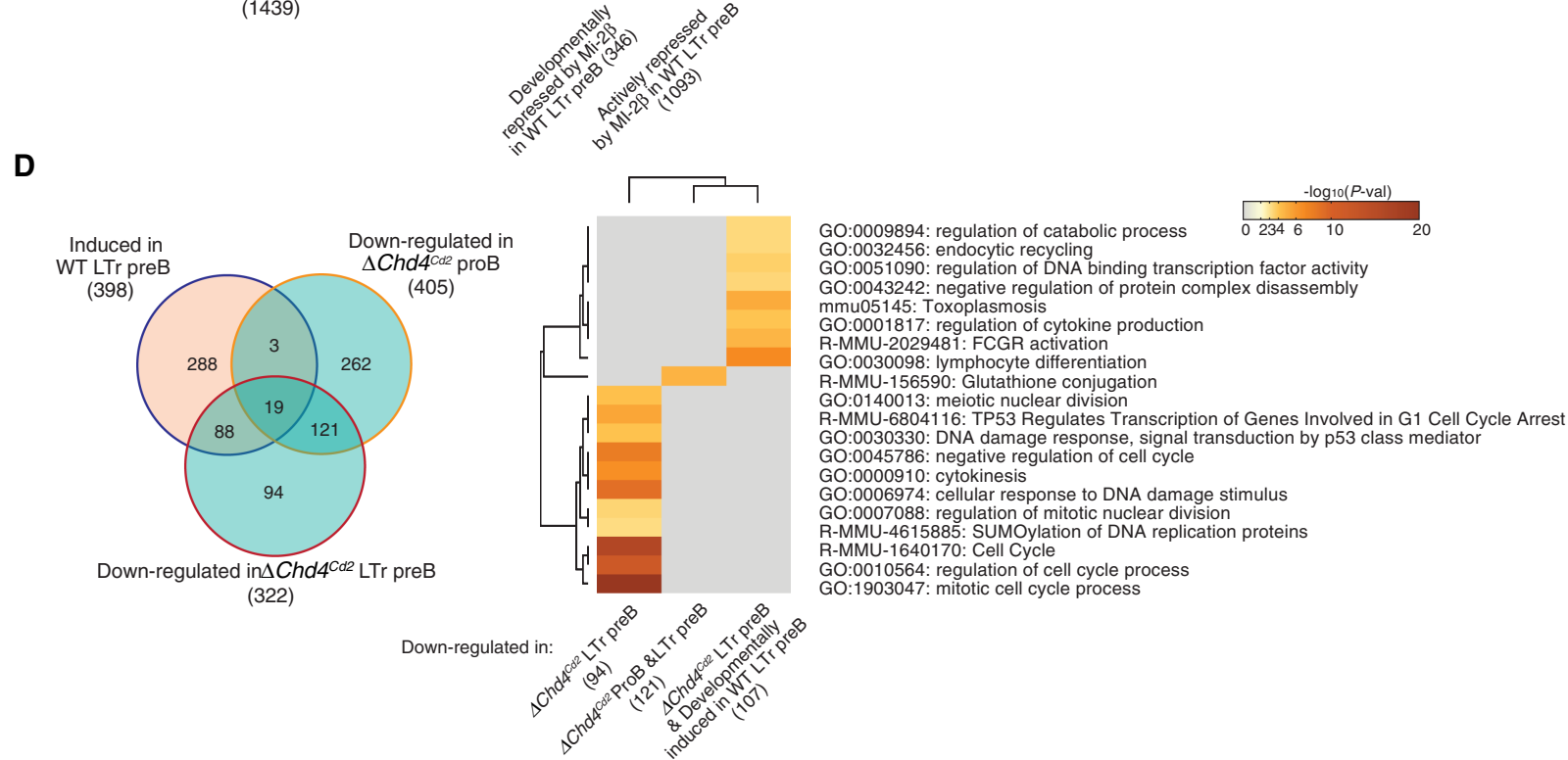

Figure 4. Transcriptional dependency of pre-B-cell precursors on Mi-2 $\beta$. (A) Pearson correlation for gene expression profiles obtained for WT and $\Delta C h d 4^{C d 2}$ pro-B and large transitional (LTr) pre-B cells. mRNA-seq for each population was performed in duplicate. $(B)$ Mean read counts for significantly up-regulated and down-regulated genes in $\Delta C h d 4^{C d 2}$ versus WT pro-B or large transitional (LTr) pre-B. Data are shown for genes with a $\log _{2}$ fold change (LFC) of $\geq 1$ and false discovery rate (FDR) of $<0.05$. The number of up-regulated or down-regulated genes is indicated in the top left or bottom right corner of the plot, respectively. $\log _{2}$ fold changes are further categorized and color-coded as indicated. $(C, l e f t)$ Venn diagrams depicting the number of up-regulated genes in $\Delta C h d 4^{C d 2}$ pro-B and large transitional (LTr) pre-B that are either developmentally repressed (346) during the pro-B-to-large transitional pre-B-cell transition in WT or actively repressed by Mi-2 $\beta$ independent of differentiation (217, 683, and 410). (Right) A heat map based on significance of functional pathway enrichment $\left[-\log _{10}(P\right.$-val $\left.)\right]$ is shown for the developmentally and actively repressed genes in $\Delta C h d 4^{C d 2}$ large transitional (LTr) pre-B cells. (D) Venn diagrams depicting the number of down-regulated genes in $\Delta C h d 4^{C d 2}$ pro-B and large transitional (LTr) pre-B that are either normally induced during pro-B-to-large transitional pre-B-cell differentiation in WT (88 and 19) or activated by Mi-2 $\beta$ in a manner that is independent of differentiation $(94,121$, and 262). (Right) A heat map for pathway analysis based on significance of enrichment $\left[-\log _{10}(P\right.$-val $\left.)\right]$ for three of these categories is shown. 
A

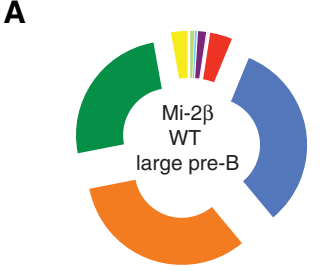

3UTR
miRNA
ncRNA
TTS
pseudo
Exon
Intron
Intergenic
Promoter
5UTR

C

\begin{tabular}{|c|c|c|c|}
\hline TF & Motif & \multicolumn{2}{|c|}{$\log _{10} P$-value $\%$ of Targets } \\
\hline CTCF & CCACCAGGTGGC & $-3.874 \mathrm{e}+03$ & $14.32 \%$ \\
\hline CTCF & GCCCTCTTCT & $-3.405 e+03$ & $7.46 \%$ \\
\hline IKAROS & TGGGAATTEAAC & $-1.735 e+03$ & $8.19 \%$ \\
\hline RUNX1 & TGTGGTII & $-1.483 e+03$ & $12.79 \%$ \\
\hline IKAROS & AACAGGAAGT & $-1.244 \mathrm{e}+03$ & $22.45 \%$ \\
\hline EBF1 & GATCCTCTGGAA & $-1.099 \mathrm{e}+03$ & $6.54 \%$ \\
\hline
\end{tabular}

B

B $\mathrm{Mi-2 \beta (CHD4) \text {IKAROS }}$

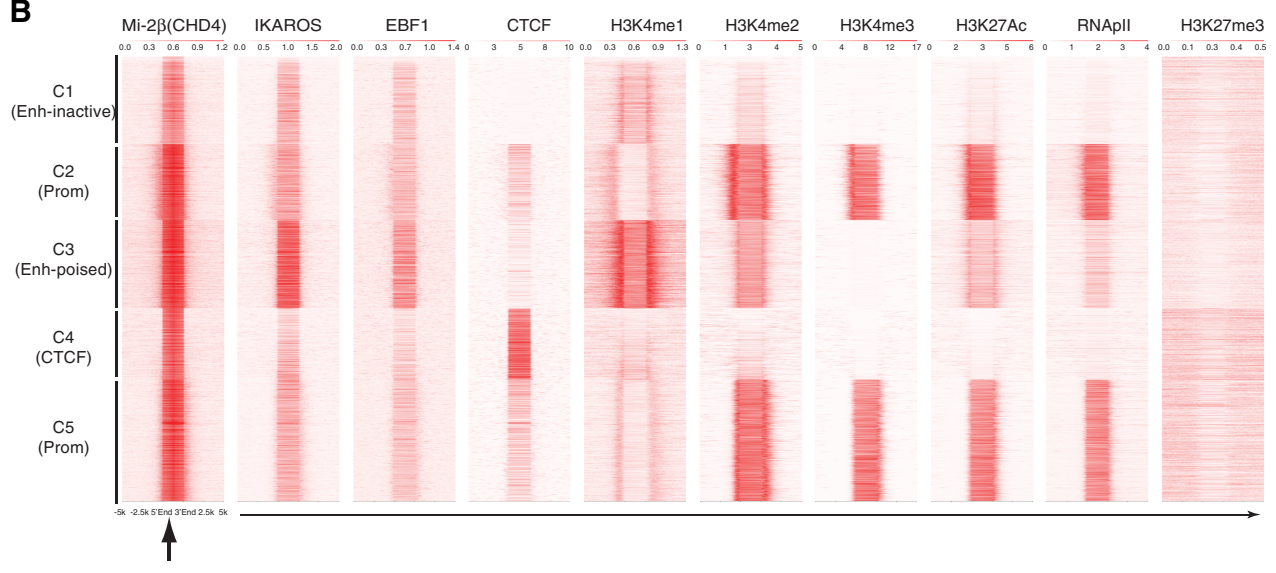

D

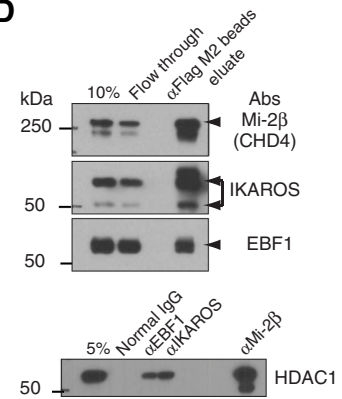

.

E

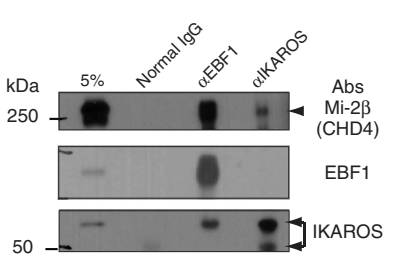

50

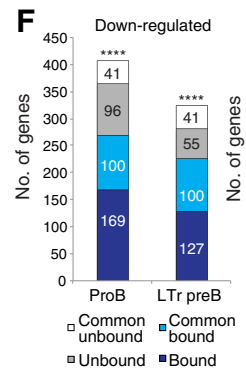

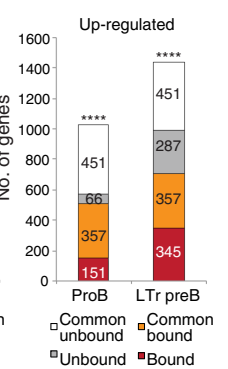

LTr preB

\begin{tabular}{|c|c|c|c|c|}
\hline & Deregulated (Up+Down) & Not deregulated & Total & \\
\hline Bound & 929 & 9444 & 10373 & $\mathrm{DF}=1$ \\
\hline Unbound & 832 & 12847 & 13679 & $z=8.473$ \\
\hline Total & 1761 & 22291 & 24052 & $P$ value $<0.0001$ \\
\hline
\end{tabular}

Figure 5. Mi-2 $\beta$ association with B-cell lineage transcription factors and chromatin landscapes. $(A)$ Genome annotation of Mi-2 $\beta$ enrichment peaks in WT large pre-B cells. $(B)$ Heat map generated by K-means clustering of reads from ChIP-seq (chromatin immunoprecipitation [ChIP] combined with high-throughput sequencing) of histone modifications and nuclear factors from WT large pre-B cells centered on Mi- $2 \beta$ enrichment peaks $( \pm 5 \mathrm{~kb})$ (indicated by a black arrow). To determine the chromatin landscapes associated with Mi-2 $\beta$ enrichment peaks, histone modifications associated with transcriptionally permissive or repressed chromatin (e.g., H3K4me1, H3K4me2, $\mathrm{H} 3 \mathrm{~K} 4 \mathrm{me} 3, \mathrm{H} 3 \mathrm{~K} 27 \mathrm{me}$, and H3K27ac) and transcription factors (IKAROS, EBF1, and RNApII) and chromatin-organizing factors (CTCF) were tested. Read distribution within Mi- $2 \beta$ enrichment peaks and size were normalized to the expected fragment size using the default spline fit algorithm of NGS.PLOT. Of the five clusters generated, two were designated as enhancers $\left(\mathrm{Cl}\right.$ and $\mathrm{C} 3$; $\mathrm{H} 3 \mathrm{~K} 4 \mathrm{me} 1^{++/+}$, $\mathrm{H} 3 \mathrm{~K} 4 \mathrm{me}^{+/-}, \mathrm{H} 3 \mathrm{~K} 4 \mathrm{me}^{-}, \mathrm{H} 3 \mathrm{~K} 27 \mathrm{ac}^{+/-}$, and $\left.\mathrm{RNApII}^{+-}\right)^{-}$, and two were designated as promoters $\left(\mathrm{C} 2\right.$ and $\mathrm{C} 5 ; \mathrm{H} 3 \mathrm{~K} 4 \mathrm{me}^{-}, \mathrm{H}_{3 \mathrm{~K}} 4 \mathrm{me} 2^{++}$, $\mathrm{H} 3 \mathrm{~K} 4 \mathrm{me}^{++}$, and $\mathrm{H} 3 \mathrm{~K} 27 \mathrm{ac}^{++}$. One of the clusters (C4) showed CTCF and Mi-2 $\beta$ enrichment but was devoid of promoter- or enhancer-associated histone modifications. $(C)$ Analysis of Mi- $2 \beta$ enrichment peaks in WT large pre-B cells for association with de novo transcription factor-binding motifs is shown. The most significantly discovered motifs, frequency (\% of targets), and $\log _{10}(P$-value $)$ are shown. $(D)$ Mi-2 $\beta$ physically associates with IKAROS and EBF1 in WT large pre-B cells. (Left) Extracts from cultured large pre-B cells from Flag-Mi-2 $\beta$ transgenic mice (Zhang et al. 2012) were immunoprecipitated with anti-Flag and analyzed by Western blotting with antibodies to IKAROS, EBF1, and Mi-2 $\beta$. Arrowheads indicate the relevant protein bands. Input (10\% of total lysate), flowthrough after anti-Flag bead extraction, and anti-Flag bead eluate were used for Western blotting. (Right) Cultured large pre-B cells from WT mice were immunoprecipitated with anti-EBF1 or anti-IKAROS and analyzed by Western blotting with antibodies to Mi-2 $\beta$, EBF1, and IKAROS. (Bottom left) Cultured large pre-B cells from WT mice were immunoprecipitated with anti-EBF1, anti-IKAROS, or anti-Mi-2 $\beta$ and analyzed by Western blotting with antibodies to HDAC1. (E) Evaluation of significant association between genes bound or not bound by Mi-2 $\beta$ in WT large pre-B cells and genes deregulated or not deregulated in $\Delta C h d 4^{C d 2}$ large transitional (LTr) pre-B cells. Data from $\chi^{2}$ analysis (two-sided) are shown. $(F)$ Bar graphs showing the frequency of association of down-regulated or up-regulated genes in $\triangle C h d 4^{C d 2}$ relative to WT B-cell precursors with Mi- $2 \beta$ enrichment peaks. Genes commonly deregulated in the two B-cell precursor subsets and bound by Mi- $2 \beta$ are indicated. Up-regulated or down-regulated genes were more frequently and significantly associated with $\mathrm{Mi}-2 \beta$ peaks compared with total number of genes, as determined by the $\chi^{2}$ test. $(* * * *) P<0.0001$. 
Motif analysis of Mi-2 $\beta$-binding sites showed a highly significant presence of CTCF, IKAROS, and EBF1 DNA recognition motifs, consistent with their observed colocalization on chromatin (Fig. 5C). Both IKAROS and EBF1 physically associated with Mi- $2 \beta$ off chromatin as well. Immunoprecipitation of $\mathrm{Mi}-2 \beta$ from large pre-B cells coprecipitated abundant IKAROS and moderate amounts of EBF1 (Fig. 5D). Immunoprecipitations of EBF1 or IKAROS coprecipitated Mi-2 $\beta$, indicating that the NuRD complex is engaged in complexes with the two B-cell lineage regulators (Fig. 5D). Other components of the NuRD complex, such as HDAC1 and HDAC2, were also coprecipitated with Mi-2 $\beta$, IKAROS, and EBF1 (Fig. 5D; data not shown).

We next tested the hypothesis that genes bound by Mi$2 \beta$ are more likely to undergo a transcriptional response upon its inactivation. The total number of annotated genes was divided into two subsets (one that was associated with Mi-2 $\beta$ peaks and a second that was not), and their transcriptional response to loss of $\mathrm{Mi}-2 \beta$ was evaluated. Notably, genes bound by Mi- $2 \beta$ were significantly more likely to show a change in transcription upon its depletion in both pro-B and large transitional pre-B cells compared with genes that were not bound by Mi-2 $\beta$ ( $\chi^{2}$ test $P$-value $<0.0001$ ) (Fig. 5E; Supplemental Fig. S5A; Supplemental Table S3). Furthermore, the majority of genes that were either induced or repressed in $\Delta C h d 4$ B-cell precursors had Mi-2 $\beta$-binding sites in their vicinity (induced $49 \%, P<0.0001$; repressed $69 \%-71 \%, P<$ 0.0001 ) (Fig. 5F).

Further evaluation of Mi-2 $\beta$ enrichment peaks associated with normally repressed genes that were induced upon its loss revealed coenrichment with IKAROS and EBF1 at sites defined as poised and inactive enhancers based on coenrichment with histone modifications and RNApII (Supplemental Fig. S5B, C1 and C5). Mi-2 $\beta$ also associated with promoters of normally repressed genes, a subset of which exhibited PRC2 activity (Supplemental Fig. S5B, C3, and C2). Co-occupancy of Mi-2 $\beta$ and CTCF in the vicinity of normally repressed genes that were induced in $\Delta C h d 4^{C d 2}$ B-cell precursors was also detected (Supplemental Fig. S5B, C4). Mi-2 $\beta$ was also distributed at active enhancers and promoters associated with the small number of genes that lost expression upon its inactivation (Supplemental Fig. S5C).

Thus, Mi-2 $\beta$ targets enhancers, promoters, and CTCF chromosome organization sites. The presence of Mi-2 $\beta$ at these regulatory elements correlates mostly with gene repression, although a role in promoting gene expression is also evident.

\section{Mi- $2 \beta$ restricts chromatin accessibility in pre- $B$-cell precursors}

A role of $\mathrm{Mi}-2 \beta$ in regulating chromatin accessibility was tested by comparing Tn5-rendering ATAC lassay for transposase-accessible chromatin) peaks in a genomewide fashion in WT and Mi-2 $\beta$-deficient B-cell precursors. Pearson's correlation analysis of ATAC-seq (ATAC and sequencing) data obtained from three independent sorted
pro-B and large transitional pre-B cells indicated that these populations were highly correlated between both the WT and $\Delta C h d 4^{C d 2}$ genotypes (Supplemental Fig. S6A). However, compared with WT, a significant change in regions of accessibility was seen in $\Delta C h d 4^{C d 2}$ pro-B or large transitional pre-B cells, which are referred to as dATAC peaks (Fig. 6A, dATAC-gained and dATAC-lost). An increase in accessibility was seen at 42000-45000 dATAC peaks in $\Delta C h d 4^{C d 2}$ B-cell precursors (Fig. 6A, dATAC-gained). A smaller number of dATAC peaks (1091-4347) showed a reduction (Fig. 6A, dATAC-lost). In both cases, the majority of dATAC peaks were located at promoter-distal sites, indicating that changes in chromatin accessibility associated with loss of Mi- $2 \beta$ occurred predominantly at nonpromoter locations (Fig. 6B; Supplemental Fig. S6B).

Of the gained dATAC peaks in $\Delta C h d 4^{C d 2}$ pro-B or large transitional pre-B cells, $55 \%-58 \%$ were observed in both cell types, indicating a sustained $\mathrm{Mi}-2 \beta$ requirement for chromatin restriction through early B-cell differentiation (Fig. 6C). In contrast, only $8 \%-32 \%$ of the dATAC peaks lost upon $\mathrm{Mi}-2 \beta$ deletion were shared between pro-B and large transitional pre-B cells, suggesting that an $\mathrm{Mi}-2 \beta$ requirement for gain in chromatin accessibility was stagespecific and progressively attenuated from pro-B to pre-B cells (Fig. 6C).

We further evaluated the Mi-2 $\beta$-dependent mechanism of chromatin restriction by examining the nature of the sites that gained chromatin accessibility in $\Delta C h d 4^{C d 2} \mathrm{~B}$ cell precursors (Fig. 6D; Supplemental Fig. S6C). Clustering of the shared dATAC-gained peaks with histone modification and transcription factor enrichment sites in WT large pre-B cells identified association with three types of regulatory elements (C1, C3, and C5) (Fig. 6D). The largest of the three dATAC-gained regulatory clusters was associated with CTCF-only binding sites (C5: $\mathrm{CTCF}^{++}, \mathrm{H} 3 \mathrm{~K} 4 \mathrm{mel}^{-}, \mathrm{H} 3 \mathrm{~K} 4 \mathrm{me} 3^{-}, \mathrm{H} 3 \mathrm{~K} 27 \mathrm{ac}^{-}$, and RNA$\left.\mathrm{pII}^{-}\right)$, the second was associated with poised enhancers (C3: H3K4me1 ${ }^{++}, \mathrm{H} 3 \mathrm{~K} 4 \mathrm{me}^{+}, \mathrm{H} 3 \mathrm{~K} 4 \mathrm{me}^{-}, \mathrm{H} 3 \mathrm{~K} 27 \mathrm{ac}^{+}$, and $\mathrm{RNApII}^{+/-}$), and the third was associated with bivalent promoters $\left(\mathrm{C} 1\right.$ : $\mathrm{H} 3 \mathrm{~K} 4 \mathrm{me}^{-}{ }^{-}, \mathrm{H} 3 \mathrm{~K} 4 \mathrm{me}^{+}{ }^{+} \mathrm{H}_{3} \mathrm{~K} 4 \mathrm{me}^{+}$, H3K27 $\mathrm{ac}^{-}$, $\mathrm{RNApII}^{-}$, and H3K27me3 ${ }^{+}$) (Fig. 6D). Notably, two of these dATAC-gained regulatory clusters enriched for CTCF or poised enhancer-associated histone marks (C5 and C3) were also strongly enriched for Mi-2 $\beta$ in WT large pre-B cells (Fig. 6D; Supplemental Fig. S6D). The two dATAC-gained clusters that were not enriched with any of the here-tested histone marks or transcription factors and therefore did not identify with any known regulatory elements were also not enriched for Mi-2 $\beta$ (C2 and C4) (Fig. 6C,D; Supplemental Fig. S6D).

The cluster of poised enhancers in WT B-cell precursors that gained accessibility upon loss of $\mathrm{Mi}-2 \beta$ was also strongly enriched for IKAROS and EBF1 in WT large preB cells (C3) (Fig. 6D; Supplemental Fig. S6E). Notably, upon loss of IKAROS in large pre-B cells, these poised enhancers showed a marked increase in transcriptionally permissive histone modifications and RNApII (Fig. 6D; Supplemental Fig. S6E; Hu et al. 2016). Thus, loss of either $\mathrm{Mi}-2 \beta$ or IKAROS at these enhancers caused an increase in 
Yoshida et al.

A

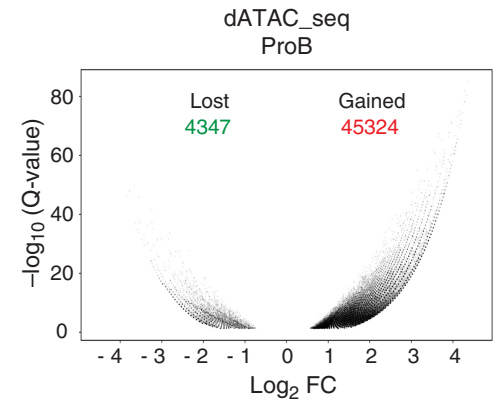

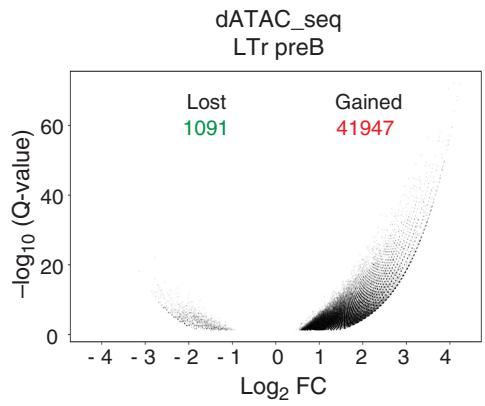

B
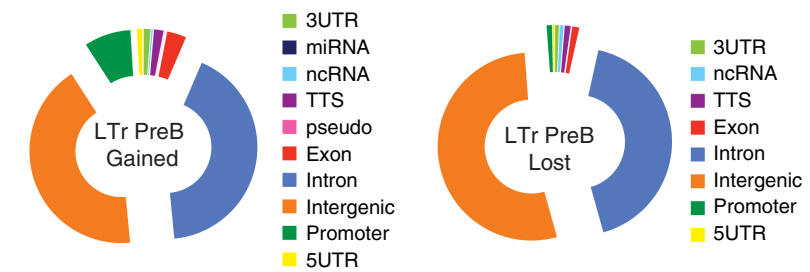

C
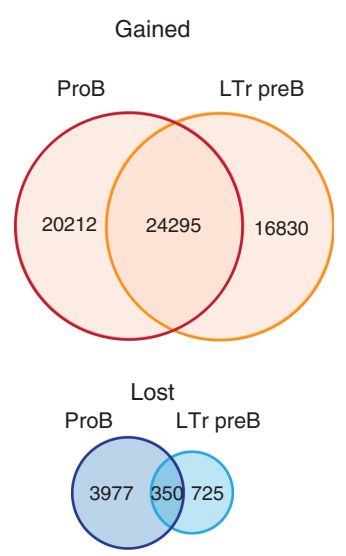

D

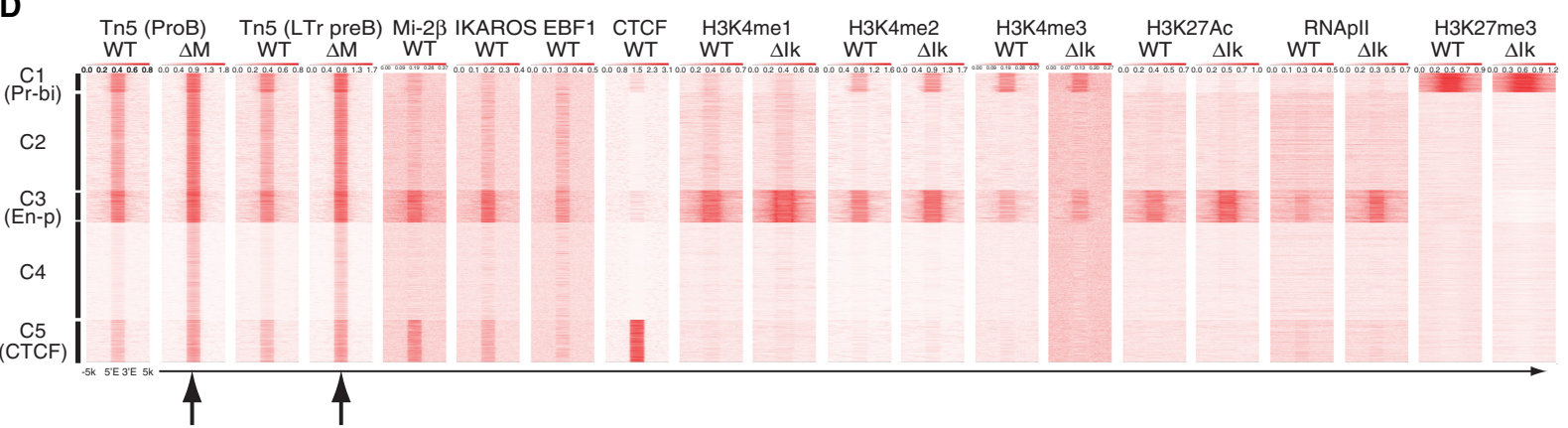

E

\begin{tabular}{|c|c|c|c|}
\hline & Gained dATAC & Not gained & Total \\
\hline BOUND & 5348 & 5325 & 10673 \\
\hline UNBOUND & 4501 & 9178 & 13679 \\
\hline Total & 9849 & 14503 & 24352 \\
\hline
\end{tabular}

$\begin{array}{lr}\text { Chi-square } & 736.6 \\ \text { DF } & 1 \\ Z & 27.14 \\ P \text { value } & <0.0001\end{array}$

F

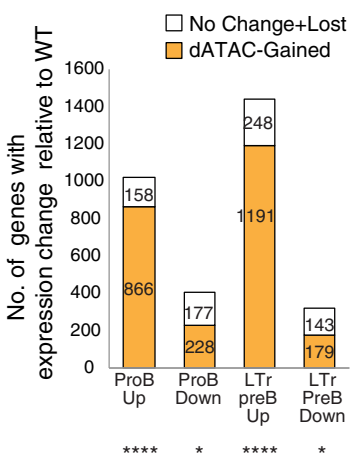

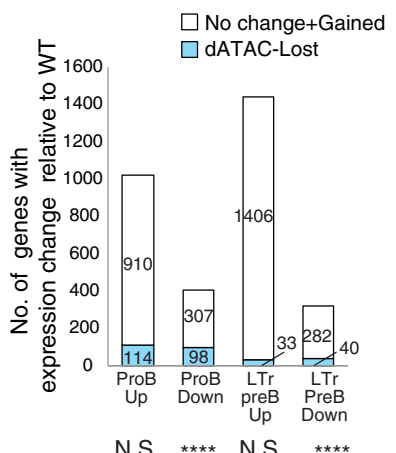

Figure 6. Mi-2 $\beta$ plays a major role in chromatin restriction in B-cell precursors. $(A)$ Volcano plots depicting changes in ATAC peaks (dATAC) between WT and $\Delta C h d 4^{C d 2}$ pro-B or large transitional (LTr) pre-B are shown. $\log _{2}$ fold change (FC) versus - log 10 (FDR-adjusted $P$-value for peak discovery [Q-value]) are plotted. The number of gained or lost sites is shown in red or green, respectively. $(B)$ Relative distribution of gained and lost dATAC peaks in $\Delta C h d 4^{C d 2}$ large transitional (LTr) pre-B cells at the indicated genomic locations. Genomic annotation of dATAC peaks was performed using Homer. (C) Overlap of gained or lost dATAC peaks in $\Delta C h d 4^{C d 2}$ pro-B and large transitional (LTr) pre-B cells. $(D)$ Heat map of K-means clustering of ChIP-seq data on histone modifications and transcription factors obtained from WT and IKAROS-deficient ( $\triangle \mathrm{Ik}$ ) large pre-B cells (Hu et al. 2016), centered on commonly gained dATAC peaks in $\Delta C h d 4^{C d 2}$ pro-B and large transitional (LTr) pre-B cells relative to WT counterparts $( \pm 5 \mathrm{~kb})$ (indicated by black arrows). Two of the five clusters were designated by histone modifications as bivalent promoters $(\mathrm{C} 1)$ and poised enhancers $(\mathrm{C} 3)$, respectively, in WT large pre-B cells, the latter cluster of enhancers becoming active in $\triangle C h d 4^{C d 2}$ and $\triangle I k E 5^{C d 2}$ large and transitional pre-B cells. Cluster C5 was associated with CTCF enrichment peaks, whereas $\mathrm{C} 2$ and $\mathrm{C} 4$ did not show any enrichment for the here-tested histone modifications or nuclear factors. $(E)$ Evaluation of the frequency of genes that show a common increase in chromatin accessibility (gained dATAC) with Mi-2 $\beta$ occupancy (bound or unbound) in $\Delta C h d 4^{C d 2}$ pro-B and large transitional (LTr) pre-B cells. Data from $\chi^{2}$ statistical analysis (two-sided) are shown. (F) Association of up-regulated or down-regulated genes with dATAC peaks. The number of up-regulated or down-regulated genes in $\Delta C h d 4^{C d 2} \mathrm{~B}$-cell precursors that show a gain (orange) or loss (light blue) in dATAC peaks is shown by histogram. Up-regulated genes were significantly associated with gained peaks, while down-regulated genes were significantly associated with lost peaks as well as gained peaks to a lesser extent, as determined by $\chi^{2}$ test. $\left({ }^{* * * *}\right) P<0.0001 ;\left(^{*}\right) P<0.05$; (N.S.) not significant. 
local accessibility and activity by two different measures: a gain in dATAC peaks in $\Delta C h d 4^{C d 2}$ pro-B and large transitional pre-B or an increase in transcriptionally permissive histone modifications in IKAROS-deficient large pre-B cells (Supplemental Figs. S6C, C3, S6E).

Genes bound by Mi-2 $\beta$ in large pre-B cells were more likely to show an increase in chromatin accessibility upon Mi-2 $\beta$ loss compared with genes that were not $\left(\chi^{2}\right.$ test $P$-value $<0.0001$ ) (Fig. 6E; Supplemental Table S1). We also tested the correlation between dATAC peaks and gene expression changes in $\Delta C h d 4^{C d 2}$ B-cell precursors (Fig. 6F). Most of the up-regulated genes in both pro$\mathrm{B}$ and large transitional pre-B cells were significantly associated with gained dATAC peaks ( $P$-values <0.0001). Down-regulated genes displayed a significant association with lost dATAC peaks ( $P$-values $<0.0001)$ and, to a lesser extent, gained dATAC peaks ( $P$-values $0.018-0.027)$.

In summary, our studies show that Mi-2 $\beta$ plays a major role in repressing gene expression and chromatin accessibility during pre-B-cell differentiation. In both pro-B and large transitional pre-B cells, genes responsive to loss of Mi-2 $\beta$ were mostly up-regulated (Fig. 4B) and associated with an increase in accessibility (Fig. 6A). Nonetheless, a role in promoting chromatin accessibility and gene expression at a much smaller number of genes and in a stage-specific manner was also evident.

\section{Mi-2 $\beta$ interaction with $B$-cell lineage transcription regulators}

Given the association between Mi-2 $\beta$, IKAROS, and EBF1 on and off chromatin, we tested for common effects on gene expression and function-based pathways (gene ontology) in pre-B-cell precursors. The transcription profiles of large pre-B cells depleted of IKAROS $\left(\Delta I k E 5^{C d 2}\right.$ ) (Joshi et al. 2014) or EBF1 $\left(\Delta E b f 1^{C d 19}\right)$ (Supplemental Fig. S7; Treiber et al. 2010) were compared with Mi-2 $\beta\left(\Delta C h d 4^{C d 2}\right)$ large transitional pre-B cells (Fig. 7A,B; Supplemental Tables S3-S7).

A major fraction $(48 \% ; 231$ of 480$)$ of the genes that were significantly up-regulated in $\Delta E b f 1^{C d 19}$ large pre-B cells was also significantly up-regulated in $\Delta C h d 4^{C d 2}$ large transitional pre-B cells (Fig. 7A; Supplemental Tables S3, S5, S6). Similarly, $28 \%$ (270 of 963) of the genes significantly derepressed in $\triangle I k E 5^{C d 2}$ large pre-B cells were also derepressed in $\Delta C h d 4^{C d 2}$ large transitional pre-B cells (Fig. 7A; Supplemental Tables S3, S4, S6). However, very few of the genes commonly repressed by $\mathrm{Mi}-2 \beta$ and $\mathrm{EBF} 1$ or $\mathrm{Mi}-2 \beta$ and IKAROS were repressed by all three factors $(6 \%, 30$ of 471) (Fig. 7A; Supplemental Table S6). Nonetheless, the two groups shared functional pathways, such as chemotaxis, cell motility, cell shape, and adhesion signaling (Fig. 7B). Examples of genes commonly repressed by Mi-2 $\beta$ and IKAROS are Zbtb7b, Plxnb1/3, Daam1, Adcy6, Tead2, and Rhol; genes commonly repressed by Mi-2 $\beta$ and EBF1 are Dntt, Rag1, Ly6a, Cxcr5, Plxnd1, Socs3, Rg11, and Sema4a; and genes commonly repressed by all three factors are Ajuba, Itga5, Dock9, P2rx7, Myh10, and Tmem176a/b (Fig. 7E; Supplemental Table S6; Supplemental Fig. S4B).
In contrast to the up-regulated genes, very few of the down-regulated genes in $\Delta C h d 4^{C d 2}$ and $\triangle I k E 5^{C d 2}$ pre-Bcell precursors were shared $(9 \% ; 24$ of 322$)$, and little overlap was seen in associated functional pathways (Fig. 7C,D; Supplemental Tables S3, S4, S7). Whereas down-regulated genes in $\Delta I k E 5^{C d 2}$ large pre-B cells highly enriched pathways of B-cell differentiation and function, down-regulated genes in $\Delta C h d 4^{C d 2}$ large transitional pre-B cells highly enriched cell cycle (Fig. 7D; Supplemental Fig. S4B). Notably, many key regulators of B-cell differentiation such as Blnk, Rag1, Rag2, and Dntt that require IKAROS for expression were not reduced by loss of Mi$2 \beta$, and, in some cases, expression was increased (Supplemental Fig. S2A). Still, the pre-B-cell differentiation genes Il2ra, Blk, and Il33 were down-regulated in both Mi-2 $\beta$ and IKAROS mutant B-cell precursors (Supplemental Fig. S4B). A larger fraction of genes down-regulated in $\Delta E b f 1^{C d 19}$ large pre-B cells was shared with $\Delta C h d 4^{C d 2}$ large transitional pre-B cells (30\% ; 37 of 125) (Fig. 7C; Supplemental Tables S3, S5, S7). Notably, genes down-regulated in either $\Delta E b f 1^{C d 19}$ or $\Delta C h d 4^{C d 2}$ large pre-B cells enriched pathways involved in cell cycle and DNA repair (Fig. 7D).

Taken together, these data establish a functional cooperation between Mi- $2 \beta$, IKAROS, and EBF1 in the repression of genes involved in cell adhesion and migration signaling pathways (model in Supplemental Fig. S8). Mi$2 \beta$ also promotes transcription of genes involved in cell proliferation, possibly through a specific collaboration with EBF1 (model in Supplemental Fig. S8). The latter effect is consistent with the loss in proliferation and cell survival in pre-B-cell precursors by loss in either Mi- $2 \beta$ or EBF1 but not IKAROS (Fig. 3A,B; Gyory et al. 2012; Joshi et al. 2014).

Increase in survival partly rescues the pre-B-cell differentiation defect

Several of the genes up-regulated by loss of Mi- $2 \beta$ in Bcell precursors have been implicated in apoptosis in neuronal cells, such as the tyrosine and serine/threonine kinases encoded by Aatk and Dapk1 (Fig. 8A; Supplemental Fig. S4B; Van Eldik 2002; Tomomura et al. 2007; Wang et al. 2007). In addition, reduction in Jak3 and Stat $5 a$, positive effectors of IL-7R signaling, and gain in expression of Socs2 and Socs3, negative regulators of IL-7R signaling, may also contribute to the reduction in IL-7R signaling, proliferation, and survival in $\Delta C h d 4^{C d 2}$ B-cell precursors (Figs. 3, 8A; Supplemental Fig. S8; Thomis et al. 1997; Yao et al. 2006; Li et al. 2010; Malin et al. 2010).

We next evaluated whether apoptosis contributed to the B-cell differentiation block in $\Delta C h d 4^{C d 2}$ mice by crossing a Bcl2-overexpressing transgene to the $\Delta C h d 4^{C d 2}$ line $\left(\Delta C h d 4^{C d 2}\right.$; Vav-Bcl2) (Ogilvy et al. 1999). Bcl2 is a prosurvival gene induced downstream from IL-7R signaling that can overcome a number of proapoptotic factors originating from deregulation of mitochondria metabolism /Youle and Strasser 2008; Kosan et al. 2010; Prudent and McBride 2017). A notable rescue in differentiation was observed 


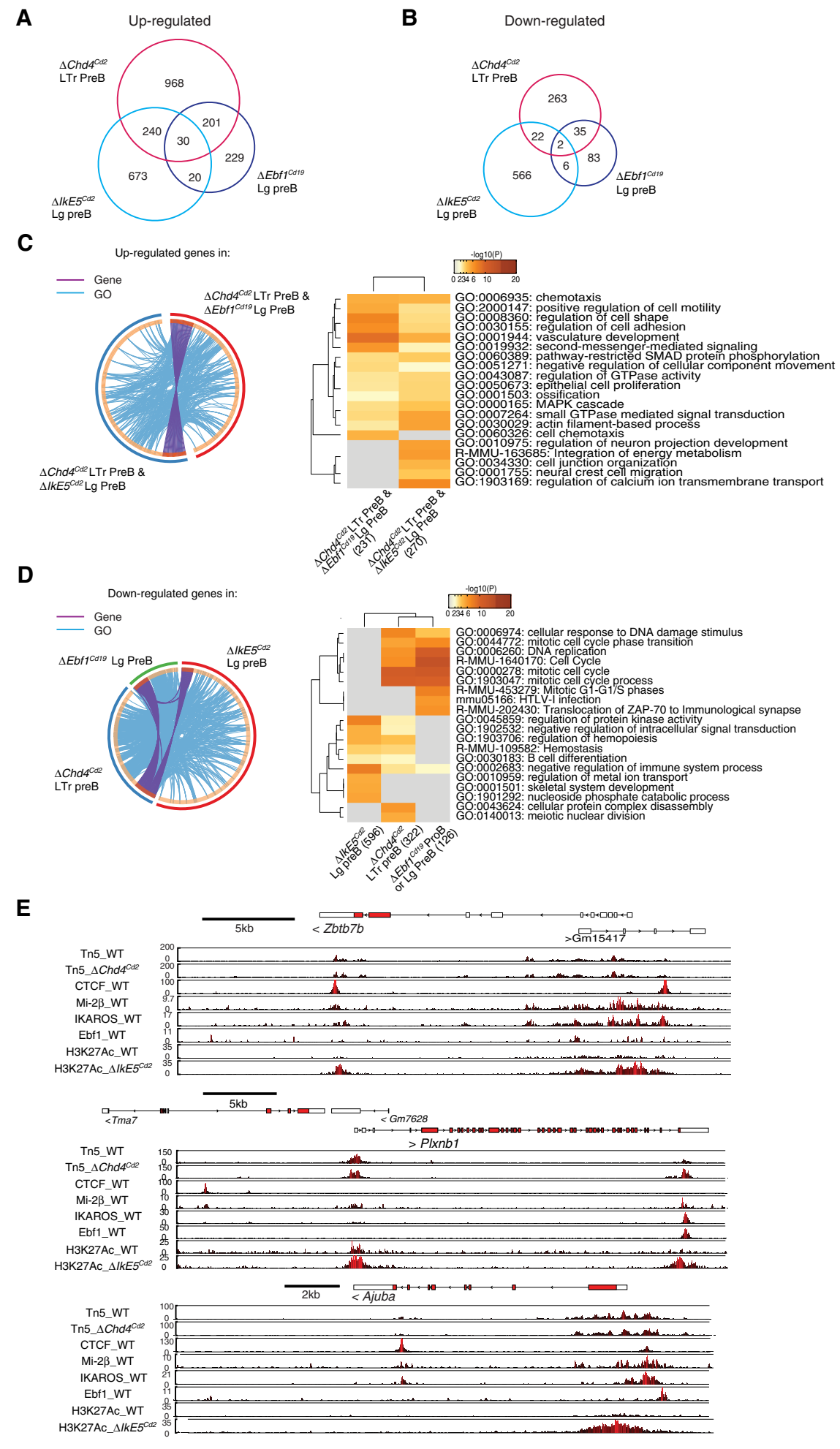

Figure 7. Mi-2 $\beta$-IKAROS-EBF1 transcriptional networks in B-cell precursors $(A, B)$ Overlap between significantly up-regulated and down-regulated genes in $\Delta C h d 4^{C d 2}$ large transitional (LTr) pre-B cells and $\triangle I k E 5^{C d 2}$ and $\triangle E b f 1^{C d 19}$ large (Lg) pre-B cells is shown. Significantly up-regulated genes in $\triangle C h d 4^{C d 2}, \Delta I k E 5^{C d 2}$, and $\triangle E b f 1^{C d 19}$ with $\log _{2}$ fold change of $\geq 1$ and FDR of $<0.05$ were tested. Significantly down-regulated genes in $\Delta C h d 4^{C d 2}$ and $\triangle I k E 5^{C d 2}$ with $\log _{2}$ fold change of $\leq-1$ and FDR of $<0.05$ and in $\triangle E b f 1^{\text {Cd19 }}$ with $\log _{2}$ fold change of $\leq-0.08$ and FDR of $<0.1$ were tested. $(C)$ Pathway analyses for two subsets of $\mathrm{Mi}$-2 $\beta$-repressed genes in B-cell precursors: genes repressed by $\mathrm{Mi}-2 \beta$ and IKAROS and genes repressed by $\mathrm{Mi}-2 \beta$ and EBF1 $(A ; 270$ and 231, respectively). Overlap in genes (purple) and pathways (blue) between the two subsets is shown by Circos. (Right) A heat map for pathway analysis based on significance of enrichment $\left[-\log _{10-}\right.$ $(P$-val)] by the two subsets of $\mathrm{Mi}-2 \beta$ repressed genes is shown. (D) Pathway analyses for genes that are significantly down-regulated in $\Delta C h d 4^{C d 2}$ large transitional (LTr) pre-B cells (322), $\triangle I k E 5^{\mathrm{Cd} 2}$ large pre-B cells (596), and $\Delta E b f 1^{\text {Cd19 }}$ large pre-B cells (126) (as in C). Overlap in genes (light blue) and pathways (purple) between the three sets of down-regulated genes is shown by Circos. (Right) A heat map for pathway analysis based on significance of gene enrichment $\left[-\log _{10}(P\right.$-val $\left.)\right]$ is shown. $(E) \mathrm{Ge}$ nome browser tracks of ATAC-seq and ChIP-seq for transcription factors and histone modifications at commonly up-regulated genes are shown. ATAC-seq $(\operatorname{Tn} 5)$ is shown for WT and $\Delta C h d 4^{C d 2}$ large transitional (LTr) pre-B cells. ChIP-seq is shown for CTCF, IKAROS, and EBF1 in WT large pre-B cells and for $\mathrm{H} 3 \mathrm{~K} 27 \mathrm{ac}$ in WT and $\triangle I k E 5^{C d 2}$ large pre-B cells. Black histograms depict sequencing read distribution, with red indicating a higher read depth.

with $\Delta C h d 4^{C d 2}$ pro-B $\left(\mathrm{c}-\mathrm{Kit}^{\mathrm{lo}} \mathrm{CD} 19^{+} \mathrm{CD} 2^{-} \mathrm{IgM}^{-}\right)$cells transiting to the small pre-B $\left(\mathrm{c}-\mathrm{Kit}^{-} \mathrm{CD} 19^{+} \mathrm{CD} 2^{+} \mathrm{IgM}^{-}\right)$cell stage of differentiation (Fig. 8B,C). In line with the increase in survival, preliminary studies show a recovery in mitochondrial mass in $\Delta C h d 4^{C d 2}$; Vav-Bcl2 mice (data not shown). Complete deletion of Chd4 in pro-B and small pre-B cells and, to a lesser extent, immature B cells
(c-Kit ${ }^{-} \mathrm{CD} 19^{+} \mathrm{CD} 2^{+} \mathrm{IgM}^{+}$) obtained from $\Delta \mathrm{Chd} 4^{\mathrm{Cd} 2}$; VavBcl2 was confirmed by genotyping (Fig. 8D). Nonetheless, the degree of differentiation rescue varied among the $\Delta C h d 4^{C d 2}$; Vav-Bcl2 mice, indicating that loss in survival could only partly account for the differentiation defect and that other pathways are likely involved (Supplemental Fig. S8). 
A

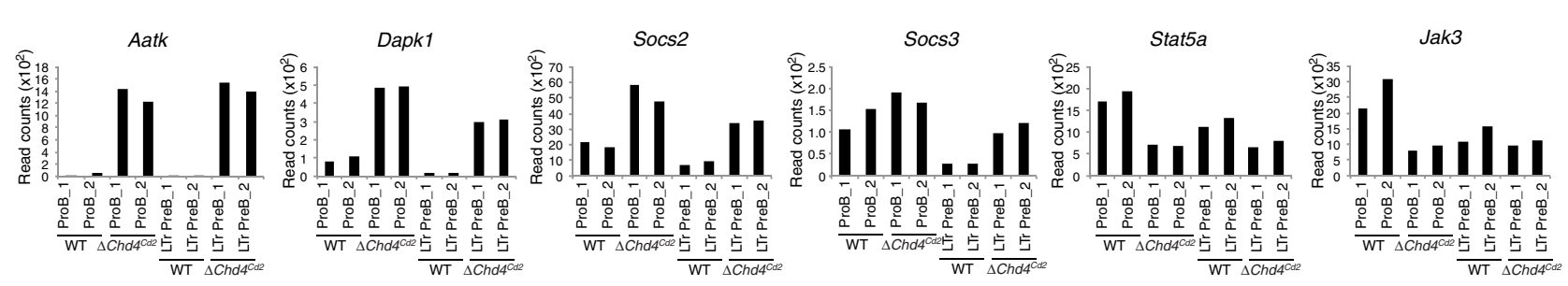

B

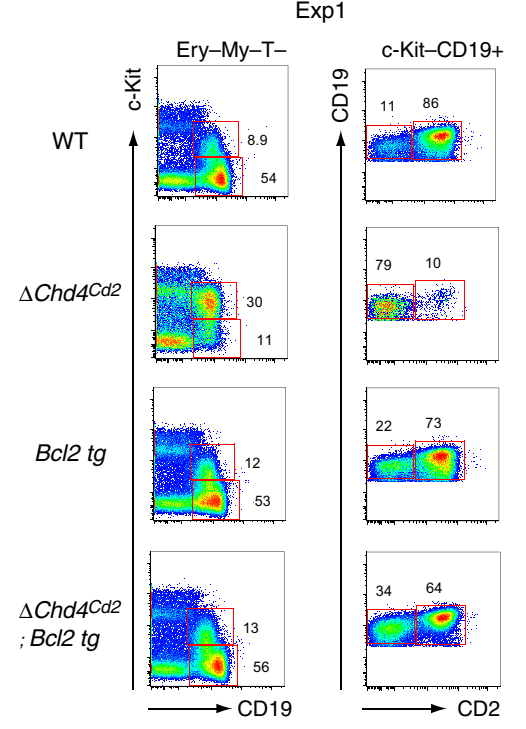

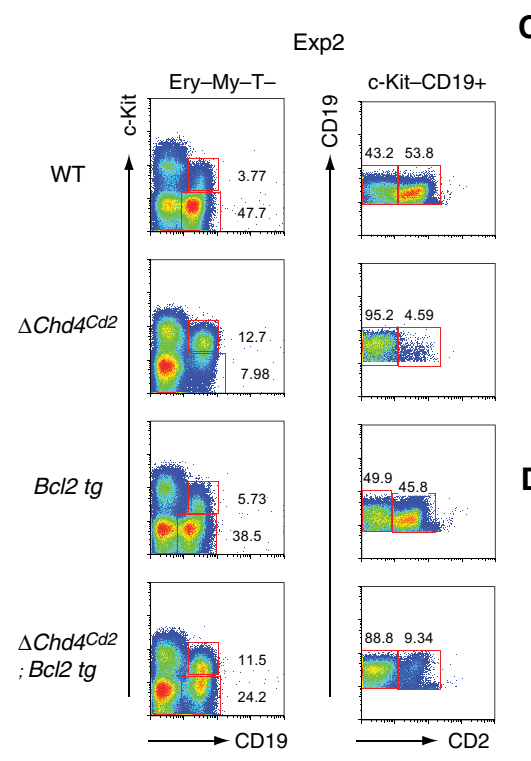

C

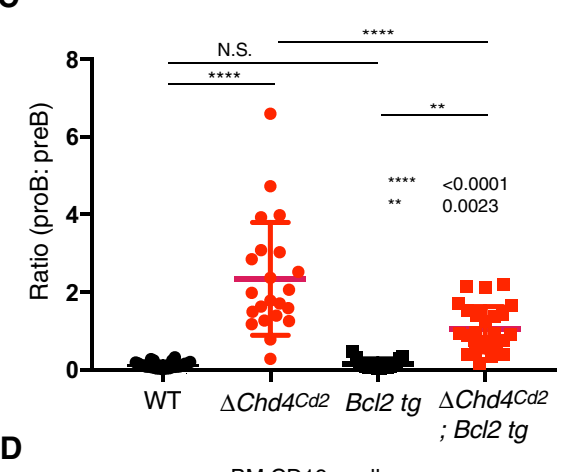

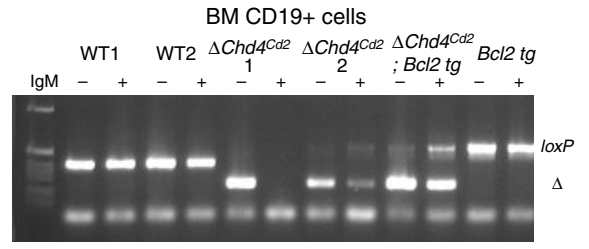

Figure 8. Increase in Bcl2 expression partly rescues differentiation of $\Delta C h d 4^{C d 2}$ B-cell precursors. (A) Induction of mRNA expression for the proapoptotic factors Aatk and Dspk1 and the suppressors of cytokine signaling Socs2 and Socs3 as well as repression of the prosurvival IL-7R signaling effectors Jak3 and Stat5a are shown in $\Delta C h d 4^{C d 2}$ pre-B-cell precursors. mRNA-seq on ex vivo isolated WT and $\Delta C h d 4^{C d 2}$ pro-B and large transitional (LTr) pre-B-cell subsets was performed in duplicates, and normalized exonic raw reads are shown. (B) Two representative analyses of early B-cell differentiation in $\Delta C h d 4^{C d 2}$ mice with overexpression of $B c l 2$ transgene $\left(\Delta C h d 4^{C d 2} ; B c l 2\right.$ tg) depicting rescue. BM cells were depleted for erythroid, myeloid, and $\mathrm{T}$ cells $\left(\right.$ Ery $\left.^{-} \mathrm{My}^{-} \mathrm{T}^{-}\right)$and stained for the B-cell differentiation markers indicated. Numbers show the percentage of cells in each gated population (red squares). (C) The ratio between pro-B $\left(\mathrm{c}-\mathrm{Kit}{ }^{\mathrm{lo}} \mathrm{CD} 19^{+}\right)$and pre-B $\left(\mathrm{c}-\mathrm{Kit}^{-} \mathrm{CD} 19^{+}\right.$) for each genotype (e.g., WT, $\Delta \mathrm{Chd} 4^{\mathrm{Cd} 2}, \mathrm{Bcl2} \mathrm{tg}$, and $\Delta C h d 4^{\mathrm{Cd} 2} \mathrm{Bcl} \mathrm{tg}$ ) is shown. The average and standard deviation are shown as black bar and red bars, respectively. Statistical significance between two samples is shown. $\left(^{* * * *}\right) P<0.0001 ;\left(^{* *}\right) P<0.0025$; (N.S.) nonsignificant. Statistical analysis was done by ordinary one-way ANOVA. (D) Analyses of deleted Chd4 exons 11-23 in $\Delta C h d 4^{C d 2}$; Bcl2 $\mathrm{tg}$ B-cell precursors. BM CD19 ${ }^{+}$cells were sorted into $\operatorname{IgM}^{-}(-)$and $\operatorname{IgM}^{+}(+)$and subjected to genomic PCR using primers that detect the predeletion loxP-containing allele $(\operatorname{lox} P)$ or the deleted locus $(\Delta)$. Two independent samples are shown from WT and $\Delta C h d 4^{C d 2}$ mice.

\section{Discussion}

Changing access of nuclear factors to developmentally regulated genes is a key mechanism in differentiation. Chromatin accessibility is controlled by enzymes that unwind chromatin fibers, remodel nucleosomes, and modify histones, thereby providing a landscape in which DNAbased processes such as transcription, DNA replication, recombination, and repair can take place. $\mathrm{Mi}-2 \beta$ is an ATP-dependent nucleosome remodeler and core component of the NuRD complex that regulates cell identity, proliferation, and genomic stability in a variety of cell types (Kim et al. 1999; Williams et al. 2004; Kashiwagi et al. 2007; Naito et al. 2007; Yoshida et al. 2008; Yamada et al. 2014; Gomez-Del Arco et al. 2016; Chaudhuri et al. 2016; Kovač et al. 2018; Ostapcuk et al. 2018; Wilczewski et al. 2018). Here we provide new insight into how Mi-2 $\beta$ functions in some of these capacities by studying its role and functional interactions with lineage-specific transcription regulators of early B-cell differentiation.

A major role for Mi-2 $\beta$ in restricting chromatin in early B-cell precursors was revealed using a high-throughput assay that directly measures chromatin accessibility (ATAC-seq). Upon Mi-2 $\beta$ loss in B-cell precursors, an extensive gain in ATAC peaks was seen across the genome. Notably, genes bound by Mi- $2 \beta$ were significantly more likely to show an increase in chromatin accessibility upon Mi-2 $\beta$ loss compared with genes that were not bound, indicating a direct role of $\mathrm{Mi}-2 \beta$ in the regulation of local chromatin structure. The majority of gained dATAC peaks at poised enhancers and CTCF sites were also bound by Mi-2 $\beta$, implicating a direct role in regulating access at enhancers and chromosome architectural elements. These enhancers were also occupied by IKAROS 
and EBF1, suggesting that the chromatin remodeler is targeted at these sites by lineage-specific DNA-binding factors. Notably, an increase in chromatin accessibility outside identifiable regulatory sites did not correlate with Mi-2 $\beta$ presence in WT cells. The co-occupancy of regulatory sites by $\mathrm{Mi}-2 \beta$ and IKAROS, Mi- $2 \beta$ and EBF1, or $\mathrm{Mi}-2 \beta$ and CTCF may reflect stable recruitment of the NuRD complex through the DNA-binding activities of these factors, whereas the absence of transcription factors from "lone" dATAC sites may reflect transient NuRD occupancy at these sites that is not readily captured by chromatin immunoprecipitation (ChIP). Alternatively, these "lone" dATAC sites may be caused by indirect effects of Mi- $2 \beta$.

At the level of transcription, two distinct roles of Mi-2 $\beta$ were deduced. A predominant role was in repression of gene expression. This appears to reflect a canonical role for Mi-2 $\beta$ and the NuRD complex with nucleosome remodeling, facilitating histone deacetylase activity and restriction of chromatin access (Tong et al. 1998). Genes repressed by Mi- $2 \beta$ enriched signaling pathways, supporting cell adhesion, actin cytoskeleton dynamics, and cell migration but also negative regulation of cell growth. Only a few of the Mi-2 $\beta$-repressed genes were normally expressed in early B-cell precursors and repressed upon differentiation, whereas the majority were not expressed in any of these cells. This suggests that Mi- $2 \beta$ may provide repression of these genes from an even earlier stage prior to B-cell lineage specification. Many of the Mi-2 $\beta$-repressed genes are involved in cell interactions with a niche microenvironment that are prevalent among progenitors of the hematopoietic, epithelial, and neuro-epithelial systems.

A relatively smaller number of genes that support basal cell functions such as cell cycle and metabolism were positively and directly regulated by $\mathrm{Mi}-2 \beta$ in B-cell precursors. This may seem at odds with a role of the NuRD complex as a repressor of chromatin accessibility. It was reported previously that other components of the NuRD complex, such as histone deacetylases, function at active genes by moderating histone acetylation and preventing internal transcription initiation and runoff, thereby increasing transcriptional output (Wang et al. 2002, 2009). A similar positive effect on transcriptional output may be provided by Mi- $2 \beta$ by facilitating histone deacetylases and restricting illegitimate entry and propagation of the basal transcription machineries. Upon Mi- $2 \beta$ loss, the relatively small reduction in expression of genes that are positively regulated by the remodeler is consistent with a hypothesis of fine-tuning rather than establishing gene expression.

A major and direct functional collaboration between $\mathrm{Mi}$ $2 \beta$ and B-cell lineage-specific transcriptional regulators was established here. First, the physical association between nucleosome remodeler (e.g., Mi-2 $\beta$ ), and lineagespecific DNA-binding factors (e.g., IKAROS or EBF1) both on and off chromatin indicated a common role in promoting B-cell differentiation. Second, loss of either Mi-2 $\beta$, IKAROS, or EBF1 arrested development at the large pre-Bcell stage and prior to the small pre-B cell, where Igk rearrangement takes place (Fig. 1A). Third, a comparison of the genes whose expression was deregulated in B-cell precur- sors deficient for either Mi-2 $\beta$, IKAROS, or EBF1 revealed an extensive and significant overlap in genes normally repressed at this stage of differentiation and induced by loss in these factors. Although the overlap in genes repressed by all three factors was relatively small, pathway analysis indicated that both subsets of Mi-2 $\beta$-repressed genes (e.g., Mi-2 $\beta$ and EBF1 or Mi-2 $\beta$ and IKAROS) supported similar cellular and molecular functions. Thus, Mi- $2 \beta$ through distinct collaborations with B-cell lineage transcription factors plays an overarching role in repressing cellular properties that are normally shed as early progenitors acquire a lineage-specific differentiation phenotype. This fits a classical model in which a lineage-specific DNAbinding factor targets a chromatin remodeling factor to restrict gene expression and allow developmental progression. Poised enhancers associated with genes repressed by Mi- $2 \beta$, IKAROS, and EBF1, such as in the adhesion-related genes Ajuba, Myh10, and Itga5, were co-occupied by the three factors, indicating a direct and shared role in repression. Loss of either Mi- $2 \beta$ or IKAROS from these enhancers caused an increase in chromatin accessibility, histone modifications, and basal transcription factor occupancy. As shown previously for IKAROS-deficient B-cell precursors, an increase in cell adhesion signaling can interfere with normal differentiation (Joshi et al. 2014).

However, the effects of Mi- $2 \beta$ loss or IKAROS loss in pre-B cells differ in other ways. In contrast to IKAROS-deficient large pre-B cells, which are normally proliferative and thrive when allowed to adhere to BM stroma (Joshi et al. 2014; Schwickert et al. 2014), Mi-2 $\beta$-deficient large pre-B cells exhibited a defect in cell cycle and survival. A reduction in the IL-7R signaling effectors pSTAT5 and pAKT in Mi-2 $\beta$-deficient B-cell precursors indicated dysfunctional IL-7R signaling that is normally required for B-cell precursor proliferation and survival (Nosaka et al. 1995; Park et al. 1995; Thomis et al. 1995; Malin et al. 2010). Increased mRNA expression of Socs2 and Socs3, negative regulators of IL-7R signaling that are normally repressed by $\mathrm{Mi}-2 \beta$, in combination with reduced $\mathrm{mRNA}$ expression of the IL-7R signaling effectors Jak3 and Stat5a, may account for the defect in IL-7R signaling. Furthermore, a reduction in mitochondrial mass and in maximal and spare respiratory capacity of mitochondrial oxidative phosphorylation in Mi- $2 \beta$-deficient B-cell precursors may also contribute to a proapoptotic phenotype. In addition, genes supporting glutathione metabolism, a major redox pathway, were dependent on Mi-2 $\beta$ for expression, indicating an additional layer of metabolism regulation by Mi-2 $\beta$. In line with this model, ectopic expression of $B c 12$, a mitochondrial prosurvival factor (Krishna et al. 2011; Aharoni-Simon et al. 2016), partly rescued the Bcell differentiation defect caused by loss of Mi- $2 \beta$.

Unlike IKAROS, several of the genes and many of the pathways that were positively regulated by $\mathrm{Mi}-2 \beta$ were also positively regulated by EBF1. These were normally genes involved in cell cycle regulation, DNA replication, and repair. In support of a common functional role in cell growth, loss of either Mi-2 $\beta$ or EBF1 caused a reduction in proliferation and survival of B-cell precursors (Gyory et al. 2012). Although both Mi-2 $\beta$ and EBF1 were 
required for expression of this group of genes, a stable association of both factors at regulatory sites associated with these genes was not observed. Further investigation into common functional targets for Mi-2 $\beta$ and EBF1 in B-cell precursors may provide more insight into how these factors coregulate cell cycle and survival.

In conclusion, our studies provide a new model by which a nucleosome remodeler, through its direct engagement with distinct lineage-specific DNA-binding factors, sets up a network of negative and positive regulatory events in gene expression that balance self-renewal, survival, proliferation, and differentiation. The combined role of Mi-2 $\beta$ with IKAROS or EBF1 in the repression of genes that support B-cell precursor interactions with the microenvironment and with EBF1 to promote cell cycle and survival is required for normal developmental progression through the large pre-B-cell checkpoint. Since the role of $\mathrm{Mi}-2 \beta$ as a positive regulator of B-cell proliferation and survival remains unaffected by loss of IKAROS, it may serve as an Achilles heel to target hard-to-treat B-cell precursor lymphoblastic leukemias that harbor IKAROS mutations and display aberrant adhesion signaling, selfrenewal, and drug resistance.

\section{Materials and methods}

Mice

All mice were bred and maintained under specific pathogen-free (SPF) conditions in the animal facility at Massachusetts General Hospital. Mice were 6-20 wk of age at the time of analyses. All animal experiments were done according to protocols approved by the Subcommittee on Research Animal Care at Massachusetts General Hospital and in accordance with the guidelines set forth by the National Institutes of Health.

\section{Antibodies}

The antibodies used and their specific clones for cell surface markers were CD3 (17A2), CD8a (53-6.7), B220 (RA3-6B2), CD19 (1D3), CD2 (RM2-5), CD43 (S7), BP-1 (FG35.4), CD25 (PC61), c-Kit (2B8), Sca-1 (D7), IL-7Ra (A7R34), Mac-1 (M1/70), B220 (RA3-6B2), CD49b (DX5), Gr-1 (RB6-8C5), and Ter119 and $\operatorname{IgM}(11 / 41)$. All antibodies were purchased from BD Biosciences, eBiosciences, BioLegend, and Tonbo Biosciences. Hybridoma supernatant was used in some cases for Ter119, B220, CD19, CD8a, and CD3a. For intracellular staining and/or Western blotting, antibodies against phosphorylated Stat5 (9351), phosphorylated Akt (4060), and phosphorylated ERK1/2 (4370) were purchased from Cell Signaling Technologies, and GAPDH was purchased from Millipore (AB2302). Antibodies used for immunoprecipitation and Western blotting (IP-Western) were anti-EBF1 (R\&D Systems, AF5165), anti-IKAROS (4E9 homemade mouse monoclonal antibody, available from Millipore [MABE912]), anti-Mi-2 $\beta$ (Abcam [3F2/4] for immunoprecipitation and 2G8 homemade mouse monoclonal antibody, available from Millipore [06-1306], for Western), and HDAC1 and HDAC2 antibodies (Cell Signaling Technologies, 34589 and 57156).

B-cell progenitor and precursor purification, flow cytometry, and cell sorting

BM cells were harvested from femurs, tibias, hips, and spines and subjected to red blood cell lysis. For CLP staining, BM cells were stained with antibodies against Ter119, B220, CD19, Mac-1, Gr1 , IgM, CD3, CD8 $\alpha, \mathrm{TCR} \beta$, and DX5 and removed with magnetic beads conjugated to goat antirat IgG (Qiagen). For B-cell precursor staining, BM cells were depleted with antibodies against Ter119, Mac-1, Gr-1, IgM, CD3, CD8 $\alpha$, TCR $\beta$, and DX5. Total and lineage-depleted BM cells were stained with the cell surface markers indicated in Figure 1 and Supplemental Figure S1. Flow cytometry was performed using a two-laser FACSCanto (BD Biosciences) or a three-laser MoFlo (Dako Cytomation). Cell sorting was performed using a three-laser MoFlo or SH800 (Sony) and the obtained files were uploaded to FlowJo (Tree Star) for further analysis.

\section{VDI rearrangement}

Sorted pro-B cells were digested overnight in lysis buffer and proteinase K. DNA was precipitated using isopropanol and washed with ethanol. PCR analysis of $I g h$ rearrangements was performed using previously published primers and conditions (Fuxa et al. 2004). PCR cycle number was adjusted to be in the linear range. Products were separated on $1.5 \%$ agarose gold gels and transferred to a positively charged nylon membrane (Amersham Biosciences). Products were hybridized to radioactive end-labeled oligonucleotides homologous to $J_{H} 3$. Oligonucleotides were described previously (Fuxa et al. 2004).

\section{Semiquantitative RT-PCR}

RNA was extracted from sorted cells using Trizol reagent (GIBCO-BRL). Reverse transcription was performed using SuperScript II (Invitrogen) primed with oligo-dT primers according to the manufacturer's protocol. cDNA concentrations were equalized after quantitative real-time PCR using an ABI Prism 7000 or Applied Biosystems 7500 thermocycler using SYBR Green reagent (ABgene). The primers used spanned at least one intron.

\section{Cell cycle analysis}

Sorted pro-B and large transitional pre-B cells were fixed by $100 \%$ ethanol overnight at $-20^{\circ} \mathrm{C}$ and stained with $50 \mu \mathrm{g} / \mathrm{mL}$ propidium iodide (PI) in the presence of $250 \mu \mathrm{g} / \mathrm{mL}$ RNase A for $30 \mathrm{~min}$ at $37^{\circ} \mathrm{C}$. DNA content was measured as intensity of PI in the linear scale of flow cytometry.

\section{Apoptosis assay}

For ex vivo apoptosis assay, BM cells from WT and $\Delta C h d 4^{C d 2}$ mice depleted with erythroid, myeloid, and $\mathrm{T}$ cells were stained with cell surface markers followed by staining with AnexinVFITC according to the manufacturer's protocol (apoptosis detection kit, BD Biosciences). For in vitro assay, sorted pro-B and large transitional pre-B cells from WT and $\Delta C h d 4^{C d 2}$ mice were cultured in the presence of $5 \mathrm{ng} / \mathrm{mL}$ IL-7 and OP9-GFP stroma cells overnight, harvested by trypsin-EDTA treatment, and stained with AnnexinV and PI. Cells were analyzed by flow cytometry.

\section{Phosflow}

Sorted pro-B and large transitional pre-B cells from WT and $\Delta C h d 4^{C d 2}$ mice were stimulated by IL-7 and anti-CD79b for 5-6 min at $37^{\circ} \mathrm{C}$, fixed with PFA at the final concentration of $2 \%$ for $20 \mathrm{~min}$ at room temperature, washed by PBS, and permeablized with $90 \%$ methanol overnight at $-20^{\circ} \mathrm{C}$. Fixed and permeabilized cells were stained by antiphospho epitope for 30 
min on ice followed by staining with a fluorescent-conjugated secondary antibody and analyzed by flow cytometry.

\section{MitoTracker staining}

B-lineage-enriched BM cells were first stained for the cell surface markers (CD19, c-Kit, CD2, IgM, and Lin) and then stained with MitoTracker Green at 50-100 nM (Invitrogen Molecular Probes) and Deep Red at $20 \mathrm{nM}$ (Invitrogen Molecular Probes) according to the manufacturer's instructions for $30 \mathrm{~min}$ at $37^{\circ} \mathrm{C}$. Cells were pelleted, resuspended, and analyzed on FACSCanto.

\section{Analyses on mitochondrial functions}

Extracellular flux was measured using the Seahorse XF Mito stress test kit (Agilent) following the manufacturer's user guide. Briefly, CD19 ${ }^{+} \mathrm{CD} 2^{-} \mathrm{IgM}^{-}$B-cell precursors were sorted from WT and $\Delta C h d 4^{C d 2}$ mice; resuspended in Seahorse XF assay medium (Agilent, 102365-100) supplemented with $10 \mathrm{mM}$ glucose, 1 $\mathrm{mM}$ sodium pyruvate, and $5 \mathrm{ng} / \mathrm{mL}$ IL-7 ( $\mathrm{pH} 7.4)$; and seeded at $1.5 \times 10^{5}$ cells per well in XFe24 culture plates precoated with Cell-Tak (BD Biosciences). The cells were incubated in a non$\mathrm{CO}_{2} 37^{\circ} \mathrm{C}$ incubator for $45 \mathrm{~min}$ prior to the assay. Oligomycin $(1.0 \mu \mathrm{M}), 1.5 \mu \mathrm{M}$ carbonyl cyanide p-trifluoromethoxyphenylhydrazone (FCCP), $0.5 \mu \mathrm{M}$ rotenone, and $0.5 \mu \mathrm{M}$ antimycin $\mathrm{A}$ were added to the medium sequentially in the assay plates provided by the kit. Oxygen consumption rate (OCR) and ECAR were measured using a Seahorse XFe24 analyzer (Agilent) and analyzed using WAVE software. Maximum respiration and spare respiratory capacity were calculated by the Mito stress test report generator.

\section{Nuclear coimmunoprecipitation}

Cell pellets were suspended in buffer A (10 mM HEPES, $1.5 \mathrm{mM}$ $\mathrm{MgCl}_{2}, 10 \mathrm{mM} \mathrm{KCl}, 0.34 \mathrm{M}$ sucrose, $10 \%$ glycerol, $0.1 \% \mathrm{NP} 40$ at $\mathrm{pH}$ 7.9) supplemented with freshly prepared complete protease inhibitor cocktail (Roche). After incubation for $5 \mathrm{~min}$ on ice, nuclei were harvested at $6000 \mathrm{~g}$ for $1 \mathrm{~min}$ at $4^{\circ} \mathrm{C}$. Nuclear pellets were washed twice in buffer A without NP40, resuspended in buffer C (20 mM HEPES, $300 \mathrm{mM} \mathrm{KCl}, 1.5 \mathrm{mM} \mathrm{MgCl}_{2}, 10 \%$ glycerol, $1 \mathrm{mM} \mathrm{DTT}$ at $\mathrm{pH} 7.9$ ), and incubated for $30 \mathrm{~min}$ at $4^{\circ} \mathrm{C}$. Extracts were centrifuged at $18,000 \mathrm{~g}$ for $20 \mathrm{~min}$, and the supernatant was dialyzed against $20 \mathrm{mM}$ HEPES, $100 \mathrm{mM} \mathrm{KCl}, 1.5 \mathrm{mM}$ $\mathrm{MgCl}_{2}$, and $10 \%$ glycerol (pH 7.9). Dialyzed nuclear extracts were used for immunoprecipitation with 300-500 $\mu$ g of nuclear extracts incubated with $4 \mu \mathrm{g}$ of factor-specific antibodies prebound to Dynabeads protein G (Life Technologies) or Flag M2 magnetic beads (Sigma) and rotated overnight at $4^{\circ} \mathrm{C}$. The antibodies used for immunoprecipitations were anti-EBF1(R\&D systems), homemade anti-IKAROS (4E9), and anti-Mi-2 $\beta$ (Abcam $3 \mathrm{~F} 2 / 4)$. The beads were washed five times with wash buffer (20 mM HEPES, $100 \mathrm{mM} \mathrm{KCl}, 1.5 \mathrm{mM} \mathrm{MgCl} 2,10 \%$ glycerol, $0.1 \% \mathrm{NP} 40$ at $\mathrm{pH} 7.9$ ) and resuspended in $30 \mu \mathrm{L}$ of $2 \times$ Laemmli SDS buffer. The samples were subjected to SDS-PAGE and Western blotting.

\section{Capillary Western blot analyses}

Capillary Western analyses were performed on a Western blot system (ProteinSimple) according to the manufacturer's instructions. In brief, sorted B-cell precursors $\left(\mathrm{CD}_{1} 9^{+} \mathrm{CD} 2^{-} \mathrm{IgM}^{-}\right)$from WT and $\Delta C h d 4^{C d 2}$ mice were lysed in RIPA buffer, and the cell lysates were diluted to $0.5 \mu \mathrm{g} / \mu \mathrm{L}$ in sample buffer. The diluted samples were combined with fluorescent master mix and heated for $5 \mathrm{~min}$ at $95^{\circ} \mathrm{C}$. The prepared samples, blocking reagent, primary antibodies (1:50 dilution for pAKT, pStat5, and pERK1/2 and 1:200 dilution for GAPDH), secondary antibodies, and chemiluminescent substrate were pipetted into designated wells in the assay plate. The electrophoresis and immunodetection steps were carried out in the fully automated capillary system. Data were analyzed using Compass software (ProteinSimple).

Construction of mRNA sequencing libraries, gene expression, and pathway analysis

RNA was extracted with Trizol (Invitrogen) and purified using the PureLink RNA minikit (Ambion). The TruSeq stranded RNA sample preparation kit was used for construction of cDNA libraries for mRNA sequencing (Illumina). The amplified libraries were multiplexed and sequenced at the Bauer Center at Harvard University. Alignment to the mouse mm10 assembly was conducted by STAR (Dobin et al. 2013). Normalization and differential expression were performed using DeSeq2 through Homer implementation of the package in R. Dot plots of normalized tags for gene subsets across WT and $\Delta C h d 4^{C d 2}$ pro-B and large transitional pre-B-cell populations were generated with ggplot2 in R. Gene ontology and annotation analysis of deregulated genes in $\Delta C h d 4^{C d 2}$ pro-B and large transitional pre-B cells were performed using Metascape (http://www.metascape.org).

\section{ChIP sequencing (ChIP-seq) libraries}

ChIP for histone modifications and transcription factors was performed from sorted WT and $\triangle I k E 5^{C d 2}$ large pre-B cells as described previously (Hu et al. 2016). In addition, ChIPs for Mi-2 $\beta$ and CTCF were performed with antibodies ab72418 (Abcam) and 2899s (Cell Signaling), respectively. DNA recovered from ChIP was used to generate libraries for sequencing. Briefly, 2.540 ng of DNA was end-repaired, end-adenylated, and then ligated with Illumina TruSeq-indexed adaptors. The ligated DNA was purified with AMPure XP beads (Beckman Coulter) and then amplified with KAPA HiFi DNA polymerase (KAPA Biosystems) for eight to 13 cycles. After amplification, the library DNA was separated on a $2 \%$ agarose gel, and DNA fragments in the 200- to 500bp range were purified with a gel DNA recovery kit (Zymo Research). The purified DNA was diluted to $10 \mathrm{nM}$ and multiplexed for sequencing at the Bauer Center Systems Biology Core at Harvard University. Image analysis and base calling were performed using the Illumina HiSeq 2000 software. Raw sequencing data sets were uploaded to DNAnexus, a cloud-based genome informatics and data management platform.

\section{ATAC-seq}

We sorted $5 \times 10^{4}$ to $10 \times 10^{4}$ pro-B and large transitional pre-B cells from WT and $\Delta C h d 4^{C d 2}$ mice and used them for ATACseq. Cells were centrifuged at $500 \mathrm{~g}$ for $5 \mathrm{~min}$ at $4^{\circ} \mathrm{C}$, washed with $1 \times$ PBS, resuspended in lysis buffer $(10 \mathrm{mM}$ Tris- $\mathrm{HCl}$ at $\mathrm{pH} 7.4,10 \mathrm{mM} \mathrm{NaCl}, 3 \mathrm{mM} \mathrm{MgCl} 2,0.1 \%$ Igepal CA-630), and immediately centrifuged at $500 \mathrm{~g}$ for $10 \mathrm{~min}$ at $4^{\circ} \mathrm{C}$. Pellets were resuspended in transposition reaction buffer $(25 \mathrm{~mL}$ of $2 \times$ Tagment buffer [Illumina, FC-121-1030], $2.5 \mathrm{~mL}$ of Tagment DNA enzyme, $22.5 \mathrm{~mL}$ of nuclease-free $\mathrm{H}_{2} \mathrm{O}$ ) for $30 \mathrm{~min}$ at $37^{\circ} \mathrm{C}$. DNA was purified with a Qiagen MinElute kit and amplified with Nextera PCR primers (Illumina Nextera index kit) and NEBNext PCR master mix (New England Biolabs, M0541) for 11 cycles. Amplified DNA was purified with a Qiagen PCR cleanup kit. Libraries were sequenced at the University of Chicago Genomics Facility. 
Analyses for ATAC-seq and ChIP-seq data

Three biological replicates from WT or $\Delta C h d 4^{C d 2}$ pro-B and large transitional pre-B cells were used to generate ATAC-seq data. The sequenced single-end reads were aligned to the mouse genome (mm10) using Bowtie2 aligner with default parameters. Picard CollectMultipleMetrics tools (Broad Institute) were used for read-mapping analysis. When necessary, duplicated reads occurring at high frequency were marked and removed using the validation stringency lenient parameter. Transcription factor peaks and histone modification-enriched regions were identified using findPeaks (Homer) algorithms (Zhang et al. 2008; Heinz et al. 2010) with input chromatin as control as described previously (Hu et al. 2016).

To deduce differential ATAC peaks (dATAC) between WT and $\Delta C h d 4^{C d 2}$ pro-B or large transitional pre-B cells, triplicate bam files generated for each condition were first merged using samtools, and then DATAC peaks were called using MACS2 with the WT merged bam file as test and the $\Delta C h d 4^{C d 2}$ merged bam file as control and vice versa. MACS2 call peak analysis was performed with -nomodel-shift 37 -extsize 73.

ATAC peak annotation or merging for pro-B or large transitional pre-B cells was performed using the Homer annotatePeaks.pl or mergePeaks commands, respectively, with maximum distance to merge set at $150 \mathrm{bp}$. K-means clustering of merged ATAC-seq and ChIP-seq bam files for histone modifications and transcription factors was performed using NGS.PLOT (Shen et al. 2014) on dATAC peaks ( $\triangle C h d 4^{C d 2}$ vs. WT) commonly enriched in pro-B or large transitional pre-B or for highly enriched Mi-2 $\beta$ peaks in WT large pre-B cells.

The Homer de novo motif discovery algorithm was used to analyze binding sites for frequently occurring DNA sequence (SQ) motifs in the vicinity of highly enriched Mi-2 $\beta$ peaks.

For data visualization, primary sequencing data were sorted, indexed, and uploaded onto a cloud-based Biodalliance genome browser (http://www.biodalliance.org). Venn diagrams were generated using the online-based Venny tool (http://bioinfogp.cnb .csic.es/tools/venny). The R Bioconductor package implemented through RStudio was used for statistical analysis and for extraction and plotting of data from next-generation sequencing-generated data files.

\section{Statistical analysis}

The statistical significance between two array groups was determined by unpaired $t$-test or ordinary one-way ANOVA with Prism 7 software. The statistical significance for association between two categorical variables was determined by $\chi^{2}$ test with Prism 7 software.

\section{Accession numbers}

The sequencing data sets generated by this study have been deposited to NCBI and are accessible through Gene Expression Omnibus series accession number GSE130315.

\section{Acknowledgments}

We thank Dr. Kristin White, Dr. Bruce Morgan, and Dr. Mariko Kashiwagi for critical review of the manuscript; Dr. Marei Dose for advice on computational analyses; Dr. Rudy Grosschedl for providing us with the Ebf1 flox/flow mice; and E.R. Wu and R. Czyzewski for mouse husbandry. This research was supported by National Institutes of Health grants 9R01HL140622 (to K. Georgopoulos), 1R21 AI124326 (to K. Georgopoulos and
T.Y.), T32 AI007512 (to Y.H.), R01CA190964 (to K. Georgopoulos), and R01AI108682 (to F.G.). K. Georgopoulos is a Massachusetts General Hospital scholar supported by Dr. Jean de Gunzburg. High-throughput DNA sequencing was performed at the Bauer Center for Genomic research, Harvard University, Cambridge, and the University of Chicago Genomics Facility.

Author contributions: T.Y., Y.H., Z.Z., A.O.E., K. Galani, H.J.S., and C.J.W. performed the experiments. K. Georgopoulos, B.M., M.Y.T., and T.Y. analyzed next-generation sequencing data. F.G. supervised ATAC studies. T.Y. made figures. T.Y. and K. Georgopoulos supervised the research and wrote the manuscript.

\section{References}

Aharoni-Simon M, Shumiatcher R, Yeung A, Shih AZ, Dolinsky VW, Doucette CA, Luciani DS. 2016. Bcl-2 regulates reactive oxygen species signaling and a redox-sensitive mitochondrial proton leak in mouse pancreatic $\beta$-cells. Endocrinology 157: 2270-2281. doi:10.1210/en.2015-1964

Avitahl N, Winandy S, Friedrich C, Jones B, Ge Y, Georgopoulos K. 1999. Ikaros sets thresholds for T cell activation and regulates chromosome propagation. Immunity 10: 333-343. doi:10.1016/S1074-7613/00|80033-3

Chaudhuri AR, Callen E, Ding X, Gogola E, Duarte AA, Lee JE, Wong N, Lafarga V, Calvo JA, Panzarino NJ, et al. 2016. Replication fork stability confers chemoresistance in BRCA-deficient cells. Nature 535: 382-387. doi:10.1038/nature18325

Corfe SA, Paige CJ. 2012. The many roles of IL-7 in B cell development; mediator of survival, proliferation and differentiation. Semin Immunol 24: 198-208. doi:10.1016/j.smim.2012.02 .001

de Boer J, Williams A, Skavdis G, Harker N, Coles M, Tolaini M, Norton T, Williams K, Roderick K, Potocnik AJ, et al. 2003. Transgenic mice with hematopoietic and lymphoid specific expression of Cre. Eur I Immunol 33: 314-325. doi:10.1002/ immu.200310005

Dobin A, Davis CA, Schlesinger F, Drenkow J, Zaleski C, Jha S, Batut P, Chaisson M, Gingeras TR. 2013. STAR: ultrafast universal RNA-seq aligner. Bioinformatics 29: 15-21. doi:10 $.1093 /$ bioinformatics/bts635

Fuxa M, Skok J, Souabni A, Salvagiotto G, Roldan E, Busslinger M. 2004. Pax5 induces V-to-DJ rearrangements and locus contraction of the immunoglobulin heavy-chain gene. Genes Dev 18: 411-422. doi:10.1101/gad.291504

Georgopoulos K. 2017. The making of a lymphocyte: the choice among disparate cell fates and the IKAROS enigma. Genes Dev 31: 439-450. doi:10.1101/gad.297002.117

Georgopoulos K, Bigby M, Wang JH, Molnar A, Wu P, Winandy S, Sharpe A. 1994. The Ikaros gene is required for the development of all lymphoid lineages. Cell 79: 143-156. doi:10 .1016/0092-8674(94)90407-3

Gomez-Del Arco P, Perdiguero E, Yunes-Leites PS, Acín-Pérez R, Zeini M, Garcia-Gomez A, Sreenivasan K, Jiménez-Alcázar M, Segalés J, López-Maderuelo D, et al. 2016. The chromatin remodeling complex Chd4/NuRD controls striated muscle identity and metabolic homeostasis. Cell Metab 23: 881892. doi:10.1016/j.cmet.2016.04.008

Gyory I, Boller S, Nechanitzky R, Mandel E, Pott S, Liu E, Grosschedl R. 2012. Transcription factor Ebfl regulates differentiation stage-specific signaling, proliferation, and survival of $\mathrm{B}$ cells. Genes Dev 26: 668-682. doi:10.1101/gad.187328.112

Hardy RR, Carmack CE, Shinton SA, Kemp JD, Hayakawa K. 1991. Resolution and characterization of pro-B and pre-pro-B 
cell stages in normal mouse bone marrow. I Exp Med 173: 1213-1225. doi:10.1084/jem.173.5.1213

Harker N, Naito T, Cortes M, Hostert A, Hirschberg S, Tolaini M, Roderick K, Georgopoulos K, Kioussis D. 2002. The CD8 $\alpha$ gene locus is regulated by the Ikaros family of proteins. Mol Cell 10: 1403-1415. doi:10.1016/S1097-2765(02)00711-6

Heinz S, Benner C, Spann N, Bertolino E, Lin YC, Laslo P, Cheng JX, Murre C, Singh H, Glass CK. 2010. Simple combinations of lineage-determining transcription factors prime cis-regulatory elements required for macrophage and B cell identities. Mol Cell 38: 576-589. doi:10.1016/j.molcel.2010.05.004

Herzog S, Reth M, Jumaa H. 2009. Regulation of B-cell proliferation and differentiation by pre-B-cell receptor signalling. Nat Rev Immunol 9: 195-205. doi:10.1038/nri2491

Hu Y, Zhang Z, Kashiwagi M, Yoshida T, Joshi I, Jena N, Somasundaram R, Emmanuel AO, Sigvardsson M, Fitamant J, et al. 2016. Superenhancer reprogramming drives a B-cell-epithelial transition and high-risk leukemia. Genes Dev 30: 1971-1990. doi:10.1101/gad.283762.116

Joshi I, Yoshida T, Jena N, Qi X, Zhang J, Van Etten RA, Georgopoulos K. 2014. Loss of Ikaros DNA-binding function confers integrin-dependent survival on pre-B cells and progression to acute lymphoblastic leukemia. Nat Immunol 15: 294-304. doi:10.1038/ni.2821

Kashiwagi M, Morgan BA, Georgopoulos K. 2007. The chromatin remodeler $\mathrm{Mi}-2 \beta$ is required for establishment of the basal epidermis and normal differentiation of its progeny. Development 134: 1571-1582. doi: $10.1242 /$ dev.001750

Kee BL. 2009. E and ID proteins branch out. Nat Rev Immunol 9: 175-184. doi:10.1038/nri2507

Kim J, Sif S, Jones B, Jackson A, Koipally J, Heller E, Winandy S, Viel A, Sawyer A, Ikeda T, et al. 1999. Ikaros DNA-binding proteins direct formation of chromatin remodeling complexes in lymphocytes. Immunity 10: 345-355. doi:10.1016/S10747613(00)80034-5

Koipally J, Georgopoulos K. 2002. A molecular dissection of the repression circuitry of Ikaros. I Biol Chem 277: 2769727705. doi:10.1074/jbc.M201694200

Kosan C, Saba I, Godmann M, Herold S, Herkert B, Eilers M, Möröy T. 2010. Transcription factor miz-1 is required to regulate interleukin-7 receptor signaling at early commitment stages of B cell differentiation. Immunity 33: 917-928. doi:10.1016/j.immuni.2010.11.028

Kovač K, Sauer A, Mačinković I, Awe S, Finkernagel F, Hoffmeister H, Fuchs A, Müller R, Rathke C, Längst G, et al. 2018. Tumour-associated missense mutations in the dMi-2 ATPase alters nucleosome remodelling properties in a mutation-specific manner. Nat Commun 9: 2112. doi:10.1038/s41467018-04503-2

Krishna S, Low IC, Pervaiz S. 2011. Regulation of mitochondrial metabolism: yet another facet in the biology of the oncoprotein Bcl-2. Biochem J 435: 545-551. doi:10.1042/BJ20101996

Li LX, Goetz CA, Katerndahl CD, Sakaguchi N, Farrar MA. 2010. A Flt3- and Ras-dependent pathway primes B cell development by inducing a state of IL-7 responsiveness. I Immunol 184: 1728-1736. doi:10.4049/jimmunol.0903023

Malin S, McManus S, Cobaleda C, Novatchkova M, Delogu A, Bouillet P, Strasser A, Busslinger M. 2010. Role of STAT5 in controlling cell survival and immunoglobulin gene recombination during pro-B cell development. Nat Immunol 11: 171-179. doi:10.1038/ni.1827

Mansfield RE, Musselman CA, Kwan AH, Oliver SS, Garske AL, Davrazou F, Denu JM, Kutateladze TG, Mackay JP. 2011. Plant homeodomain (PHD) fingers of CHD4 are histone $\mathrm{H} 3-$ binding modules with preference for unmodified $\mathrm{H} 3 \mathrm{~K} 4$ and methylated H3K9. I Biol Chem 286: 11779-11791. doi:10 $.1074 /$ ibc.M1 10.208207

Medvedovic J, Ebert A, Tagoh H, Busslinger M. 2011. Pax5: a master regulator of B cell development and leukemogenesis. Adv Immunol 111: 179-206. doi:10.1016/B978-0-12-385991-4 $.00005-2$

Mercer EM, Lin YC, Murre C. 2011. Factors and networks that underpin early hematopoiesis. Semin Immunol 23: 317-325. doi:10.1016/j.smim.2011.08.004

Mullighan CG. 2012. Molecular genetics of B-precursor acute lymphoblastic leukemia. I Clin Invest 122: 3407-3415. doi:10.1172/JCI61203

Naito T, Gómez-Del Arco P, Williams CJ, Georgopoulos K. 2007. Antagonistic interactions between Ikaros and the chromatin remodeler Mi-2 $\beta$ determine silencer activity and $C d 4$ gene expression. Immunity 27: 723-734. doi:10.1016/j.immuni.2007 .09 .008

Ng SY, Yoshida T, Zhang J, Georgopoulos K. 2009. Genome-wide lineage-specific transcriptional networks underscore Ikarosdependent lymphoid priming in hematopoietic stem cells. Immunity 30: 493-507. doi:10.1016/j.immuni.2009.01.014

Nosaka T, van Deursen JM, Tripp RA, Thierfelder WE, Witthuhn BA, McMickle AP, Doherty PC, Grosveld GC, Ihle JN. 1995. Defective lymphoid development in mice lacking Jak3. Science 270: 800-802. doi:10.1126/science. 270.5237 .800

Ogilvy S, Metcalf D, Print CG, Bath ML, Harris AW, Adams JM. 1999. Constitutive Bcl-2 expression throughout the hematopoietic compartment affects multiple lineages and enhances progenitor cell survival. Proc Natl Acad Sci 96: 1494314948. doi:10.1073/pnas.96.26.14943

Ostapcuk V, Mohn F, Carl SH, Basters A, Hess D, Iesmantavicius V, Lampersberger L, Flemr M, Pandey A, Thoma NH, et al. 2018. Activity-dependent neuroprotective protein recruits HP1 and CHD4 to control lineage-specifying genes. Nature 557: 739-743. doi:10.1038/s41586-018-0153-8

Park SY, Saijo K, Takahashi T, Osawa M, Arase H, Hirayama N, Miyake K, Nakauchi H, Shirasawa T, Saito T. 1995. Developmental defects of lymphoid cells in Jak3 kinase-deficient mice. Immunity 3: 771-782. doi:10.1016/1074-7613(95) 90066-7

Prudent J, McBride HM. 2017. The mitochondria-endoplasmic reticulum contact sites: a signalling platform for cell death. Curr Opin Cell Biol 47: 52-63. doi:10.1016/j.ceb.2017.03.007

Rickert RC, Roes J, Rajewsky K. 1997. B lymphocyte-specific, Cre-mediated mutagenesis in mice. Nucleic Acids Res 25: 1317-1318. doi:10.1093/nar/25.6.1317

Rolink A, Grawunder U, Winkler TH, Karasuyama H, Melchers F. 1994. IL-2 receptor a chain (CD25, TAC) expression defines a crucial stage in pre-B cell development. Int Immunol 6: 12571264. doi:10.1093/intimm/6.8.1257

Schatz DG. 2004. V(D)J recombination. Immunol Rev 200: 5-11. doi:10.1111/j.0105-2896.2004.00173.x

Schwickert TA, Tagoh H, Gultekin S, Dakic A, Axelsson E, Minnich M, Ebert A, Werner B, Roth M, Cimmino L, et al. 2014. Stage-specific control of early B cell development by the transcription factor Ikaros. Nat Immunol 15: 283-293. doi:10 $.1038 /$ ni. 2828

Shah D, Sah S, Nath SK. 2013. Interaction between glutathione and apoptosis in systemic lupus erythematosus. Autoimmun Rev 12: 741-751. doi:10.1016/j.autrev.2012.12.007

Shen L, Shao N, Liu X, Nestler E. 2014. . ngs.plot: Quick mining and visualization of next-generation sequencing data by integrating genomic databases. BMC Genomics 15: 284. doi:10 $.1186 / 1471-2164-15-284$ 
Spanopoulou E, Roman CA, Corcoran LM, Schlissel MS, Silver DP, Nemazee D, Nussenzweig MC, Shinton SA, Hardy RR, Baltimore D. 1994. Functional immunoglobulin transgenes guide ordered B-cell differentiation in Rag-1-deficient mice. Genes Dev 8: 1030-1042. doi:10.1101/gad.8.9.1030

Sridharan R, Smale ST. 2007. Predominant interaction of both Ikaros and Helios with the NuRD complex in immature thymocytes. I Biol Chem 282: 30227-30238. doi:10.1074/jbc .M702541200

Thomis DC, Gurniak CB, Tivol E, Sharpe AH, Berg LJ. 1995. Defects in B lymphocyte maturation and $\mathrm{T}$ lymphocyte activation in mice lacking Jak3. Science 270: 794-797. doi:10 $.1126 /$ science.270.5237.794

Thomis DC, Lee W, Berg LJ. 1997. T cells from Jak3-deficient mice have intact TCR signaling, but increased apoptosis. $I$ Immunol 159: 4708-4719.

Tomomura M, Morita N, Yoshikawa F, Konishi A, Akiyama H, Furuichi T, Kamiguchi H. 2007. Structural and functional analysis of the apoptosis-associated tyrosine kinase (AATYK) family. Neuroscience 148: 510-521. doi:10.1016/j .neuroscience.2007.05.048

Tong JK, Hassig CA, Schnitzler GR, Kingston RE, Schreiber SL. 1998. Chromatin deacetylation by an ATP-dependent nucleosome remodelling complex. Nature 395: 917-921. doi:10 $.1038 / 27699$

Treiber T, Mandel EM, Pott S, Györy I, Firner S, Liu ET, Grosschedl R. 2010. Early B cell factor 1 regulates B cell gene networks by activation, repression, and transcriptionindependent poising of chromatin. Immunity 32: 714-725. doi:10.1016/j.immuni.2010.04.013

Van Eldik LJ. 2002. Structure and enzymology of a death-associated protein kinase. Trends Pharmacol Sci 23: 302-304. doi:10 .1016/S0165-6147(02)02049-7

Wang JH, Nichogiannopoulou A, Wu L, Sun L, Sharpe AH, Bigby M, Georgopoulos K. 1996. Selective defects in the development of the fetal and adult lymphoid system in mice with an Ikaros null mutation. Immunity 5: 537-549. doi:10.1016/ S1074-7613(00)80269-1

Wang JH, Avitahl N, Cariappa A, Friedrich C, Ikeda T, Renold A, Andrikopoulos K, Liang L, Pillai S, Morgan BA, et al. 1998. Aiolos regulates $\mathrm{B}$ cell activation and maturation to effector state. Immunity 9: 543-553. doi:10.1016/S1074-7613(00) 80637-8

Wang A, Kurdistani SK, Grunstein M. 2002. Requirement of Hos2 histone deacetylase for gene activity in yeast. Science 298: 1412-1414. doi:10.1126/science.1077790

Wang WJ, Kuo JC, Ku W, Lee YR, Lin FC, Chang YL, Lin YM, Chen CH, Huang YP, Chiang MJ, et al. 2007. The tumor suppressor DAPK is reciprocally regulated by tyrosine kinase Src and phosphatase LAR. Mol Cell 27: 701-716. doi:10.1016/j .molcel.2007.06.037

Wang Z, Zang C, Cui K, Schones DE, Barski A, Peng W, Zhao K. 2009. Genome-wide mapping of HATs and HDACs reveals distinct functions in active and inactive genes. Cell 138: 1019-1031. doi:10.1016/j.cell.2009.06.049

Watson AA, Mahajan P, Mertens HD, Deery MJ, Zhang W, Pham P, Du X, Bartke T, Zhang W, Edlich C, et al. 2012. The PHD and chromo domains regulate the ATPase activity of the human chromatin remodeler CHD4. I Mol Biol 422: 3-17. doi:10.1016/j.jmb.2012.04.031

Welinder E, Mansson R, Mercer EM, Bryder D, Sigvardsson M, Murre C. 2011. The transcription factors E2A and HEB act in concert to induce the expression of FOXO1 in the common lymphoid progenitor. Proc Natl Acad Sci 108: 17402-17407. doi:10.1073/pnas.1111766108

Whyte WA, Bilodeau S, Orlando DA, Hoke HA, Frampton GM, Foster CT, Cowley SM, Young RA. 2012. Enhancer decommissioning by LSD1 during embryonic stem cell differentiation. Nature 482: 221-225. doi:10.1038/nature10805

Wilczewski CM, Hepperla AJ, Shimbo T, Wasson L, Robbe ZL, Davis IJ, Wade PA, Conlon FL. 2018. CHD4 and the NuRD complex directly control cardiac sarcomere formation. Proc Natl Acad Sci 115: 6727-6732. doi:10.1073/pnas.1722219115

Williams CJ, Naito T, Arco PG, Seavitt JR, Cashman SM, De Souza B, Qi X, Keables P, Von Andrian UH, Georgopoulos K. 2004. The chromatin remodeler Mi- $2 \beta$ is required for CD4 expression and $\mathrm{T}$ cell development. Immunity 20: 719-733. doi:10.1016/j.immuni.2004.05.005

Winandy S, Wu L, Wang JH, Georgopoulos K. 1999. Pre-T cell receptor (TCR) and TCR-controlled checkpoints in T cell differentiation are set by Ikaros. J Exp Med 190: 1039-1048. doi:10 $.1084 /$ jem.190.8.1039

Yamada T, Yang Y, Hemberg M, Yoshida T, Cho HY, Murphy JP, Fioravante D, Regehr WG, Gygi SP, Georgopoulos K, et al. 2014. Promoter decommissioning by the NuRD chromatin remodeling complex triggers synaptic connectivity in the mammalian brain. Neuron 83: 122-134. doi:10.1016/j.neuron.2014 .05 .039

Yao Z, Cui Y, Watford WT, Bream JH, Yamaoka K, Hissong BD, Li D, Durum SK, Jiang Q, Bhandoola A, et al. 2006. Stat5a/b are essential for normal lymphoid development and differentiation. Proc Natl Acad Sci 103: 1000-1005. doi:10.1073/pnas .0507350103

Yoshida T, Ng SY, Zuniga-Pflucker JC, Georgopoulos K. 2006. Early hematopoietic lineage restrictions directed by Ikaros. Nat Immunol 7: 382-391. doi:10.1038/ni1314

Yoshida T, Hazan I, Zhang J, Ng SY, Naito T, Snippert HJ, Heller EJ, Qi X, Lawton LN, Williams CJ, et al. 2008. The role of the chromatin remodeler $\mathrm{Mi}-2 \beta$ in hematopoietic stem cell selfrenewal and multilineage differentiation. Genes Dev 22: 1174-1189. doi:10.1101/gad.1642808

Youle RJ, Strasser A. 2008. The BCL-2 protein family: opposing activities that mediate cell death. Nat Rev Mol Cell Biol 9: 47-59. doi:10.1038/nrm2308

Zhang Y, Liu T, Meyer CA, Eeckhoute J, Johnson DS, Bernstein BE, Nusbaum C, Myers RM, Brown M, Li W, et al. 2008. Model-based analysis of ChIP-seq (MACS). Genome Biol 9: R137. doi:10.1186/gb-2008-9-9-r137

Zhang J, Jackson AF, Naito T, Dose M, Seavitt J, Liu F, Heller EJ, Kashiwagi M, Yoshida T, Gounari F, et al. 2012. Harnessing of the nucleosome-remodeling-deacetylase complex controls lymphocyte development and prevents leukemogenesis. Nat Immunol 13: 86-94. doi:10.1038/ni.2150 


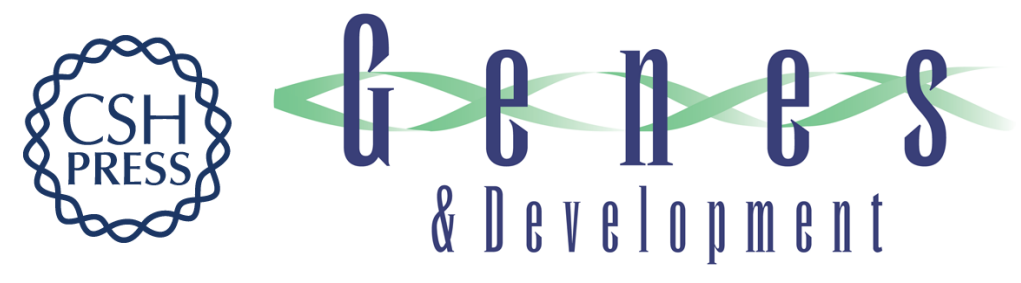

\section{Chromatin restriction by the nucleosome remodeler Mi-2 $\beta$ and functional interplay with lineage-specific transcription regulators control B-cell differentiation}

Toshimi Yoshida, Yeguang Hu, Zhihong Zhang, et al.

Genes Dev. 2019, 33: originally published online May 23, 2019

Access the most recent version at doi:10.1101/gad.321901.118

Supplemental Material

References

Creative

Commons

License

Email Alerting

Service
http://genesdev.cshlp.org/content/suppl/2019/05/20/gad.321901.118.DC1

This article cites 69 articles, 22 of which can be accessed free at: http://genesdev.cshlp.org/content/33/13-14/763.full.html\#ref-list-1

This article is distributed exclusively by Cold Spring Harbor Laboratory Press for the first six months after the full-issue publication date (see http://genesdev.cshlp.org/site/misc/terms.xhtml). After six months, it is available under a Creative Commons License (Attribution-NonCommercial 4.0 International), as described at http://creativecommons.org/licenses/by-nc/4.0/.

Receive free email alerts when new articles cite this article - sign up in the box at the top right corner of the article or click here.

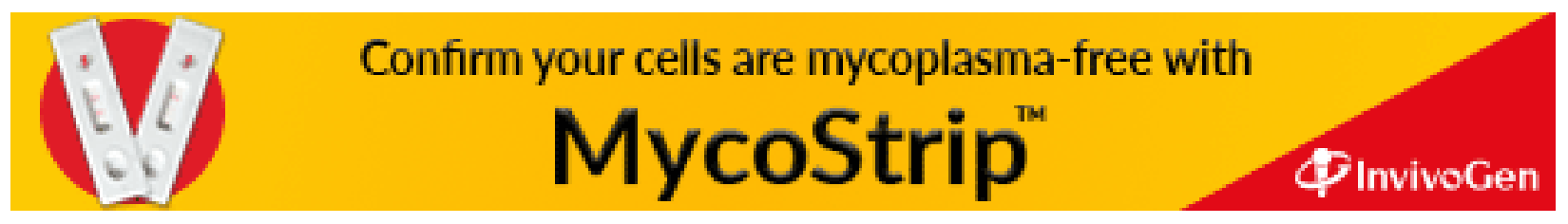

